Papers and Proceedings of the Royal Society of Tasmania, Volume 112, 1978.

(ms. received 1.9.1977)

\title{
A PLEISTOCENE SPINY ANTEATER FROM TASMANIA (MONOTREMATA: TACHYGLOSSIDAE, ZAGLOSSUS)
}

by Peter Murray

Tasmanian Museum, Hobart

(with two tables, 18 text-figures and two plates)

\section{ABSTRACT}

A partially articulated skeleton of a fossil Zaglossus from a cave located near Montagu, Tasmania, differs sufficiently from Zaglossus bruijni to warrant its assignment to another species. The Montagu specimen is probably conspecific with "Echidna (Proechidna)" robusta Dun, 1895 which includes the misnomer "Ornithorhynchus maximus" Dun 1895. The Montagu fossil is also conspecific with Zaglossus harpissoni Scott and Lord, 1921, from King Island Tasmania. Echidna owenii and Echidna ramsayi are suggested to be nomina vana because they are represented by undiagnostic fragments. Comparison of the cranium and certain postcranial elements of the Montagu Zaglossus with Zaglossus bruigni reflect possible differences in feeding behavior between the two species.

\section{INTRODUCTION}

Pleistocene echidnas belonging to the genus zaglossus have been known since 1868 (Krefft 1868). Fragmentary remains of these animals have subsequently been recovered from swamp and cave deposits of every Australian state except the Northern Territory (Owen 1884; Wilkinson 1887; Glauert 1914; Scott and Lord 1921). A confused synonomy has resulted due to nomenclatural changes and a lack of systematic comparison of the material (table 1). Many more fragments of fossil echidnas are present in museum collections around Australia. Unfortunately, they have generated little interest and are not often reported in the literature. Abundant remains of the genus have been recovered from several recently excavated cave deposits in New South Wales, South Australia and Victoria (J. Hope, N. Pledge, T. Rich and E. Gill pers. comm.), and in New Guinea ( $J$. Hope pers. comm.).

The recent acquisition of a nearly perfect cranium and associated major postcranial elements in partial articulation from a Tasmanian cave deposit provides the necessary material to initiate a reassessment of zaglossus fossils. The following is a detailed description of the Montagu ZagZossus material (Z.2031, Z.2032, Tas. Mus.) with some accompanying tentative remarks on its affinity with the living Zagzossus bruijni and fossil Zaglossus specimens described in the literature.

\section{MATERIALS}

Specimens numbered 22031 and 22032 (Tasmanian Museum) have been assigned to Zaglossus robusta Dun, 1895 (figure 1) of which the following materials are described:

Cranium lacking mandibles and zygomatic arches; rostrum of second individual broken at level of groove for ascending facial vein; vertebrae: C 2-4, T 5-16 (?), L 1-2, S1; left and right humeri, left humerus of second individual; paired clavicles and episternum; left and right scapulae, right scapula of second individual; left and right femora; left and right fibulae; left and right tibiae, innominate bones lacking ilia.

A complete Zaglossus britini skeleton (M9852) was supplied by the Australian Wational Muscum, Sydney. Two nartially prepared skeletons in the C.S.I.R.O. collection, 
FOSSIL ECHIDNA REMAINS AS REPORTED IN THE LITERATURE

Species

Elements recovered

Echidna oweni=ramsayi

Echidna owenierambayi

Proechidna robusta (=Omithorhymohus manimus) zaglossus hacketti

Zaglossus harrissoni

Zaglossus (Z2031-2)

Tachyglossus sp.

"armbone"
element unknown
element unknown

1. Type $E$. oweni

2. Type $E$. ramsayi

3. Type for species given

4. Queensland Museum, Brisbane

5. Mining and Geological Museum, Sydney

distal phalange

femur

humerus ${ }^{2}$

skuIl and atlas ${ }^{3}$

humerus

pelvic girdle

femora

radius

femur

vertebrae

innominate

humeri

scapulae

femora

tibia

fibulae

femur

lement unknown
Loca1ity

Age

Author

Darling Downs, Queensland ${ }^{4}$ Pleistocene

Pleistocene

Dum, 1895

distal humerus fragment ${ }^{3}$

scapula and episternum

clavicles and episternum

femur and humerus fragment ${ }^{3}$ King Island, Tasmania ${ }^{9}$

Scotchtown Cave, Tasmania ${ }^{9}$ Pleistocene

P1eistocene

Scott and Lord, 1921

Montagu Caves, Tasmania

Pleistocene

Murray

clavicles and episternum

Wellington Caves ${ }^{6} \quad$ Pleistocene

Mammoth Caves ${ }^{7}$

Darling Dows, Queentand10 Pleistoce Glauert, 1910

Mowbray Swanp, Tas 10

$\begin{array}{ll}\text { Mowbray Swamp, Tas. } & \text { Pleistocene } \\ \text { Scotchtown Cave, Tas. }{ }^{10} & \text { Pleistocene }\end{array}$

Dun, 189

Gi 11 and Banks, 1956

Gi11 and Banks, 1956

7. Western Australian Museum and Art Gallery

8. Department of Anatomy, University of Tasmania

9. Queen Victoria Museum, Launceston

9. Queen Victoria Nused
10. Location unknown. 
Canberra were also examined. This material was supplemented by reference to Gervais (1878). Measurements of a series of 2 . bruijni skulls were kindly taken for me by Dr. L. Weller (Department of Anatomy, University of Tasmania) and Prof. J. Johnson (Dept. of Biophysics, Michigan State University), when they visited the American Museum of Natural History in 1976. Observations on muscular anatomy are based on dissections and dried muscle preparations of Tachyglossus aculeatus setosus prepared according to instructions given in Hildebrand (1968). A Powerline Model 72 speed engraver was found useful for removing hard, calcareous matrix from the skeleton.

$$
\text { LOCALITY, STRATIGRAPHY, }{ }^{14} \mathrm{C} \text { DETERMINATION }
$$

A detailed description of the Montagu site is given in Murray and Goede (1977) The Zaglossus skeleton was recovered from a pocket within a steeply inclined shaft plugged by consolidated cave fill. The pocket also contained a complete pair of mandibles, a femur, a tibia and paired innominates of sthenums aff. occidentalis. Thyzacoleo carmifex, Protemnodon anak, Zygomaturus (?) and Palorchestes sp. were recovered from stratigraphically equivalent positions within the cave. The fauna closely resembles other Australian Late Quaternary fossil assemblages. The fauna was contained within the uppermost of three strata of cave sediments. Bone collagen from this stratum (Bed 3B) yielded a ${ }^{14} \mathrm{C}$ determination of $10,000 \pm 700$ (R5001/2) radiocarbon years. The date is considered a minimum age. However, geomorphological evidence a1so suggests that the deposit may postdate the maximum cold phase of the last glaciation. Dominance of solution weathering products within Bed 3B implies a less cold climate and greater abundance of moisture that followed a cold period denoted by a predominance of angular (frost-fractured) products in Bed 2 .

\section{SYSTEMATICS}

Subclass PROTOTHERIA

Order MONOTREMATA

Fami ly TACHYGLOSSIDAE

Zaglossus robusta Dun, 1895

1868 Echidna owenii Krefft, Ann. Mag. Nat. Hist., 4(1), 113, 114; figures 1-3. (Nomen vanum).

1884 Echidna ramsayi Owen, Phil. Trans. R. Soe., 175, 273-5, P1. 14, figures 1-3. (Nomen vanum).

1895 Echidna (Proechidna) robusta Dun, Rec. Geol. Surv. N.S.W., 4, 121-3, P1. 11, Figures 5, 6, P1. 12 .

1895 Ormithorhynchus maximus Dun, Rec. Geol. Sum. N.S.W., 4, 123-5, P1. 11, Figures 1-4.

1921 Zaglossus harrissoni Scott and Lord, Pap. Proc. R. Soc. Tasm., 13-15, P1. 5.

Holotype - Cranial fragment, Australian Museum no. F.51451; atlas vertebra, F. 51452 and a right humerus ("Omithorhynchus maximus"), F.51453. Echidna owenii and Echidna ramsayi are considered nomina vana in the sense given by Simpson (1945, p.30; 1948, p.31) and subsequently employed by Welles and Gregg (1971, p.6). Both species designations are based on fragmentary remains of humeri. Echidna owenii consists of a fragment of distal articular surface and is undiagnostic at the species 1 eve 1. Echidna ramsayi is based on more complete but inadequate material for species assignment. Echiana owenii and E. ramsayi are therefore validly established names that may apply only to these type specimens.

Type Locality - Auriferous drift in a limestone cavern entered via the Canadian Lead mine shaft, Gulgong Gold Field, N.S.W.

Age - Considered to be Pliocene.

Referred Specimens - Right femur (Zaglossus harpissoni Scott and Lord 1921), (1965: 39: 
TABLE 2

METRIC ATTRIBUTES (IN MM) OF SKULLS OF ZAGLOSSUS BRUTJNI EMPLOYED IN SCATTER DIAGRAMS

\begin{tabular}{crrr}
$\mathrm{A}$ & \multicolumn{1}{c}{$\mathrm{B}$} & $\mathrm{C}$ & $\mathrm{D}$ \\
& & & \\
154.0 & 130.9 & 96.1 & 13.4 \\
- & 136.2 & 105.3 & 16.8 \\
186.0 & 160.5 & 118.0 & 16.2 \\
193.0 & 164.9 & 123.5 & 17.7 \\
- & 148.8 & 107.4 & 16.2 \\
- & 151.8 & 113.0 & 16.3 \\
- & 156.2 & 117.4 & 16.4 \\
- & - & 123.8 & 16.7 \\
168.0 & 145.5 & 108.7 & 14.0 \\
- & 154.2 & 108.6 & 14.8 \\
158.0 & 135.1 & 97.2 & 14.5 \\
- & 121.7 & - & 17.0 \\
- & 130.2 & 92.9 & 16.0 \\
- & 181.9 & 131.5 & 17.9 \\
- & - & 123.6 & 16.6 \\
141.2 & 120.0 & 86.0 & 12.0 \\
165.0 & 139.0 & 95.5 & 21.6
\end{tabular}

CALCULATIONS PERTAINING TO ROSTRAL DECURVATION

$\begin{array}{lccc} & & \text { E } & F \\ \text { Tas. Mus. Z2031 } & 264.3 & 30.0 \\ \text { Aust. Mus. M9852 } & 121.5 & 57.6 \\ \text { Gervais-1 } & 223.5 & 42.2 \\ \text { Gervais-2 } & 170.0 & 50.0 \\ \text { AMNH 195369 } & 184.6 & 47.3 \\ \text { AMNH 190863 } & 185.8 & 52.7 \\ \text { AMNH 190862 } & 222.2 & 42.4 \\ \text { AMNH 195370 } & 164.1 & 49.0 \\ \text { AMNH 194702 } & 187.8 & 40.8 \\ \text { AMNH 190861 } & 245.1 & 43.6 \\ \text { AMNH 157073 } & 169.5 & 45.2 \\ \text { AMNH 157072 } & 197.4 & 40.0 \\ \text { AMNH 195372 } & 227.9 & 40.1 \\ \text { AMNH 104020 } & 249.0 & 36.0 \\ \text { AMNH 66194 } & 239.8 & 35.3 \\ \text { AMNH 195371 } & 195.9 & 45.6 \\ \text { Harvard Mus } & 12414 & 263.0 & 33.1\end{array}$

Gervais-1 and 2 measured from natural sized 1ithographs after Gervais (1878).

E. Radius (mm)

F. Degrees subtending $\theta$

5/Q.V.M. 13), fragment of rostrum, (22032), Montagu Caves, Northwestern Tasmania; nearly complete cranium and associated postcranial elements described herein (Z2031), Montagu Caves.

Fragmentary remains of a second individual were recovered from an adjacent, unconnected cave system. These include a rostrum fragment, a humerus fragment and a scapula. The specimen was associated with a predominantly modern fauna. A single Sthenurus upper molar suggests a pre-Holocene date for the deposit.

With the possible exception of Zagzossus "Proechidna" robusta Dun, all reported ZagZossus ("Echidna", "Proechidna") fossils date from the Quaternary (Bartholomai 1972, 1975; Tedford 1966). Dun (1895, p.120) considered Proechidna robusta to be from pliocene auriferous drift. However, it is possible that the Canadian Lead faunal deposit is contemporary with nearby Wellington Caves breccia.

Tachyglossus remains appear to be less common than Zaglossus in pleistocene sites even though the former is frequently found in Holocene cave and dune deposits. At least some Pleistocene Tachyglossus fossils are larger than the living $T$. aculeatus (Glauert 1910). Zaglossus and Tachyglossus remains occur in the same deposits suggesting that they were sympatric during the Pleistocene. Van Deusen and George (1969, p.13-14) consider the two genera to be allopatric in New Guinea where Tachyglossus prefers drier, more open forest habitats. 

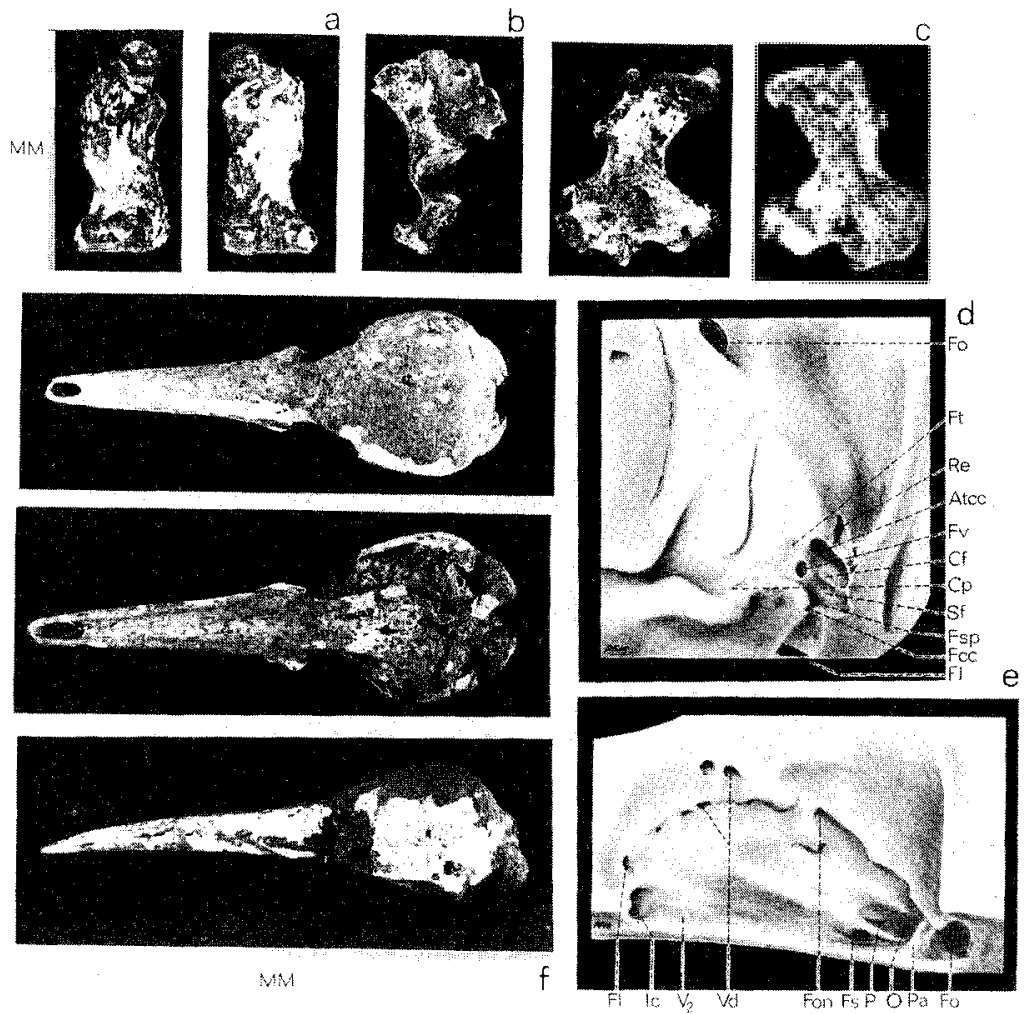

PLATE 1. - Fossil remains of 22031 -32; a, posterior and anterior aspects of left femur; b, left scapula (Z2032); c, right humerus; d, drawing of the ear region; e, drawing of the orbit; $f$, dorsal, palatal and lateral aspects of cranium; Fo, foramen pseudovale; Ft, tympanic fossa; Re, recessus epitympanicaus; Atcc, apertura tympanica canalis facialis; Fv, vestibular foramen; Cf, crista facialis; Cp, crista parotica; Sf, sulcus facialis; Fsp, foramen stylomastoideum primitivum; Fcc, Foramen into canalis craniotympanalis; Fj, jugular foramen; F1, lacrimal foramen; $I c$, infraorbital canal; $V_{2}$, groove for maxillary nerve; $V d$, diploic veins; Fon, orbitonasal foramen; Fs, sphenopalatine foramen; $\mathrm{P}$, foramen pterygoid canal; $\mathrm{Pa}$, palatine.

\section{DESCRIPTION}

Cranium (Table 2; Figs 3-5; P1ate 1; Appendix)

The terminology applied to the descriptive anatomy of the fossil cranium is derived from Tandler (1902) and Kuhn (1971); the ear region follows simpson (1938).

Neurocranium

The braincase is large and globular with a slight flattening of the supra.occipital. The maximum width of the neurocranium is located immediately anterior to 


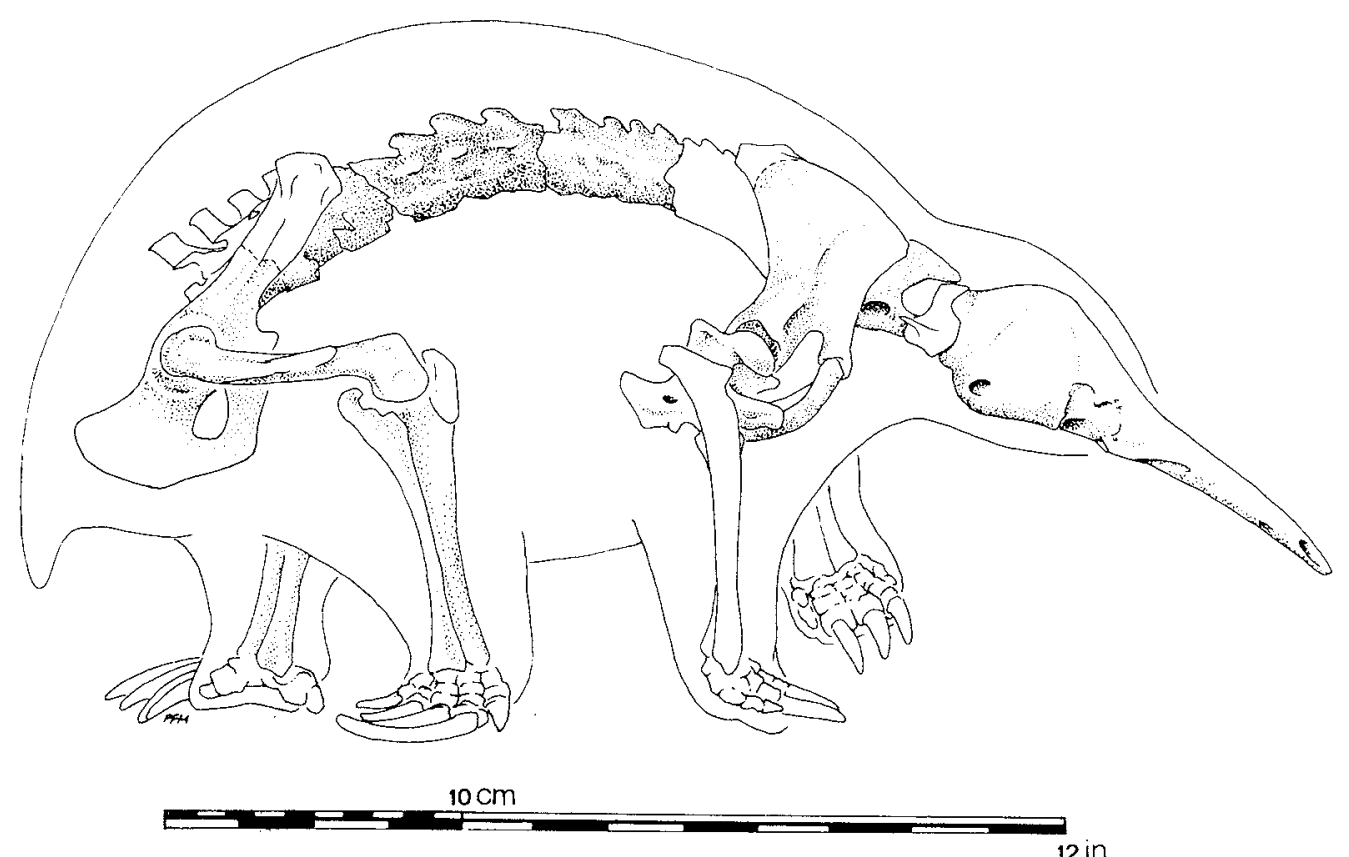

FIG. 1. - Restoration of the skeleton of Zaglossus robusta (Tas. Mus. 22031) from Montagu, Tasmania. Recovered elements are stippled.

the temporal foramina. The cranial bones are thin and internally bear the impressions of the sulci and gyri of the brain. The sutures are obliterated throughout. The anterior portion of the neurocranium grades smoothly into an elongated rostrum. Low, rounded crests arch across the braincase. These are the anterior nuchal line representing the trapezius anterior muscle and the posterior line for the m. rhomboideus cervicis. The anterior (superior) nuchal line extends from the superoposterior edge of the orbit to the midline, terminating at the approximate area of the occipitoparietal junction. The posterior nuchal line describes a more transverse arc across the squamosal to merge with the anterior line. The inferior nuchal line for the attachment of semispinalis capitus and complexus major muscles is indistinct. The supraoccipital bone presents a broad, smooth surface for the attachment of the rectus capitus dorsalis major and minor muscles.

A shallow, circular pit is present in the supraoccipital immediately superior to 
Peter Murray

the foramen magnum. The superomedial aspect of the occipital condyles are bounded by a pair of shallow triangular depressions. The occipital condyles are large, elongated, somewhat rectangular articular surfaces with the long axis diverging from the horizontal at approximately 43 degrees. The condyles bulge prominently at the back of the neurocranium. The supra and exoccipital bones are produced outwards around the foramen magnum.

The foramen magnum is rectangular in shape. Large temporal foramina for the diploic arteries are located within a shallow depression formed by the squamosal. The squamosal itself is thin and high. Inferiorly, it defines a deep posterior temporal fossa.

\section{Rostrum}

The rostrum is very broad, moderately elongated and gently decurved. The distal termination is blunt, rounded and thin dorsoventrally. The entire structure is moderately compressed. The rostrum gradually increases in width to the level of the infraorbital foramen. At this point it is broadly connected to the braincase. A shallow depression occupies the midiine in the position of the median suture of the frontal bones. It extends anteriorly to the approximate position of

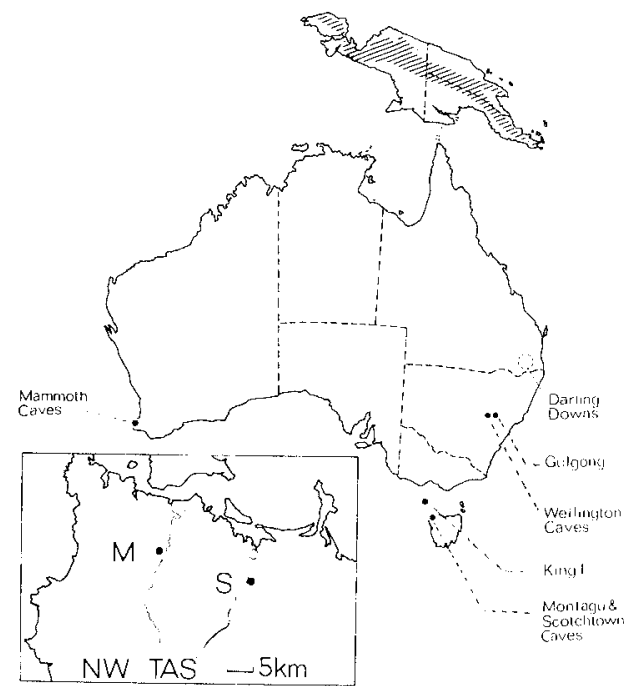

FIG. 2. - Map showing some of the localities from which Zaglossus fossils have been recovered. Hatchures denote the present range of Zaglossus bruijni. M, Montagu Caves; S, Scotchtown Cave, located in northwestern Tasmania. the nasofrontal junction. The perimeter of this area is perforated by numerous, small foramina. A faint median groove continues from the nasofrontal depression to the posterior margin of the opening"of the external nares. The aperture for the external nares is an elongated, oval fenestra, slightly widened anteriorly.

The premaxillary suture is open. Large, elongated maxillofacial foramina are located on the lateral and inferolateral margins of the rostrum near the base of the nasal aperture and more posteriorly to a point about two-fifths of the distance to the infraorbital canal.

\section{Orbit (Plate le)}

The shallow orbit has an irregular but definable superior border penetrated by several large foramina for the diploic veins. A low triangular protuberance on the mid-superior border serves for the attachment of the fiberous aponeurosis of the anterior temporalis muscle. The large infraorbital canal is located at the internal angle of the root of the maxillary process of the zygomatic arch. The optic fissure is subdivided by a pair of low crests which separate the opthalmic nerve from nerves II, III, IV and VI superiorly and the maxillary division of the trigeminal inferiorly. A small sphenopalatine foramen located anterior to the optic fissure receives branches from the infraorbital artery and nerve. The foramen of the pterygoid canal pierces a process of the palatine bone which separates the optic fissure from foramen pseudovale. Foramen pseudovale $\left(V_{3}\right)$ is relatively large and circular in shape. The superior 

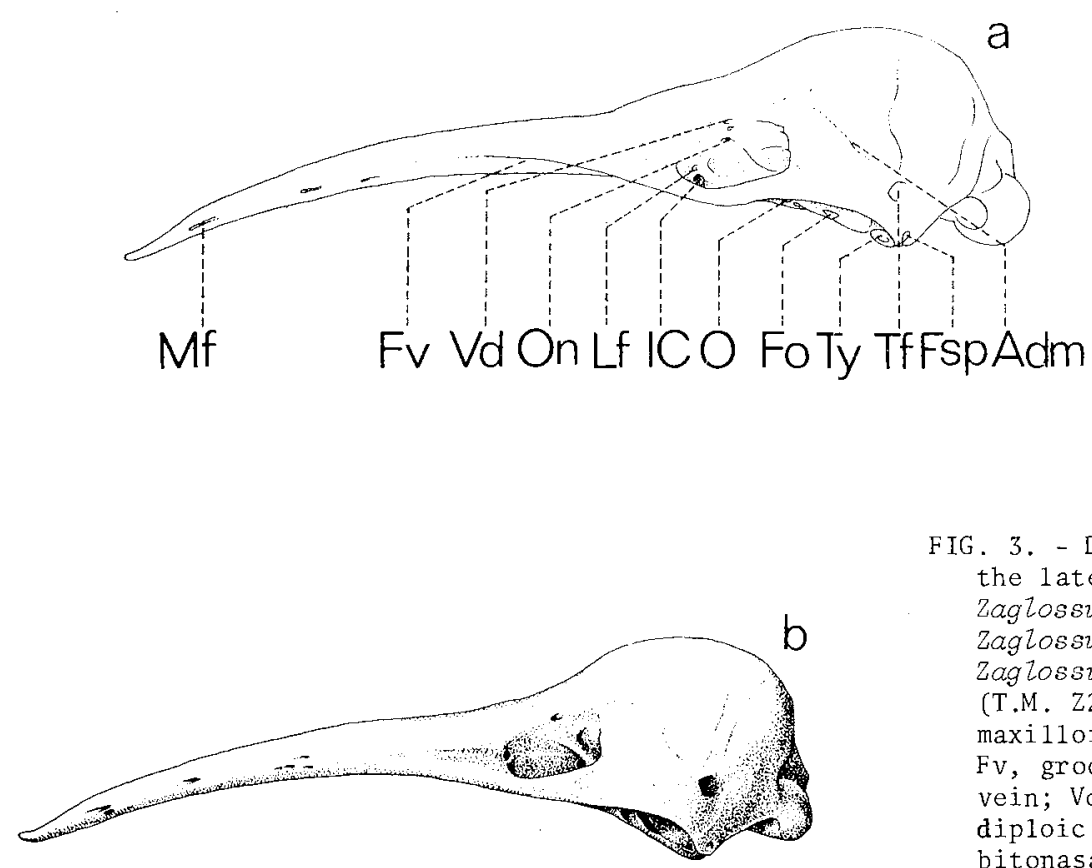

FIG. 3. - Drawings of the lateral aspect of Zaglossus skulls, a-c, Zaglossus bruijni; d, zaglossus robusta (T.M. Z2031); Mf, maxillofacial foramen; Fv, groove for facial vein; $\mathrm{Vd}$, foramen for diploic vein; On, orbitonasal foramen, Lf, 1 acrimal foramen; Ic, infraorbita 1

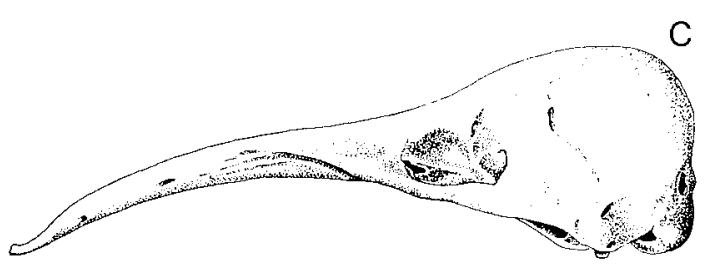
canal; 0 , orbital fissure; Fo, Foramen pseudovale; $\mathrm{Ty}$, tympanic cavity; $\mathrm{Tf}$, temporal foramen; $\mathrm{Sp}$, foramen stylomastoideum primitivum; adm, Arteria diploica magna (a, b, after Gervais, 1878).

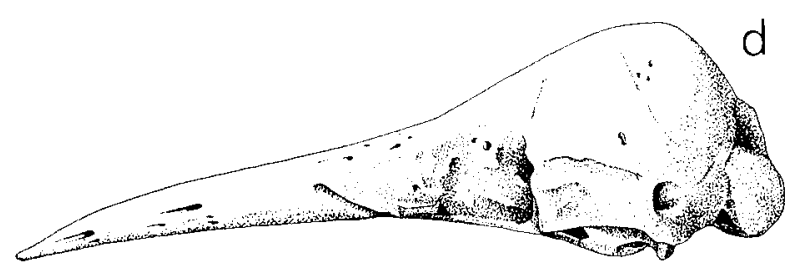

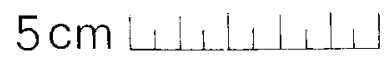




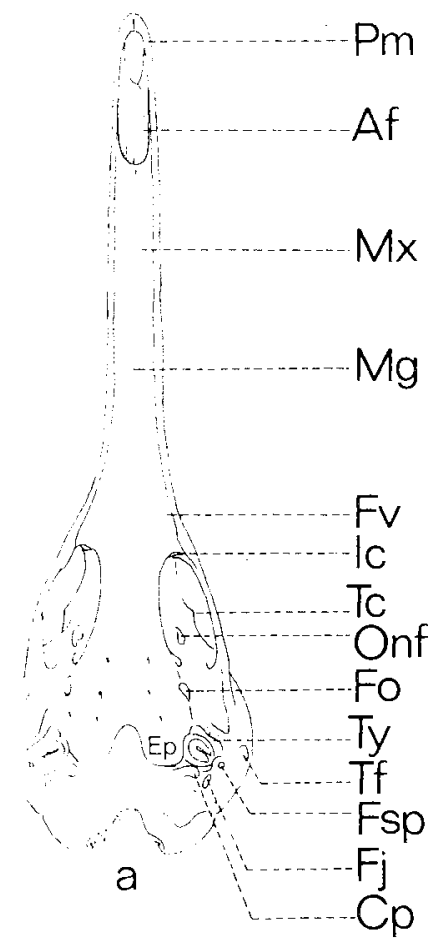

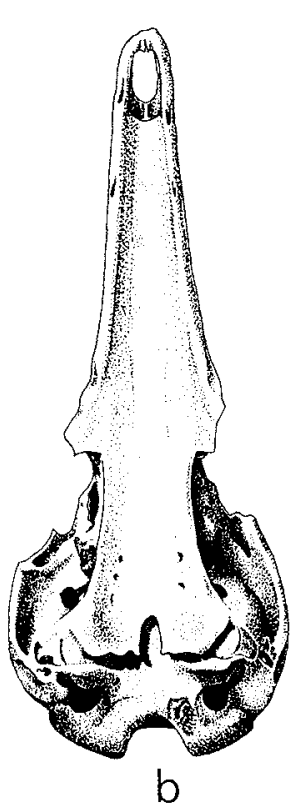

b

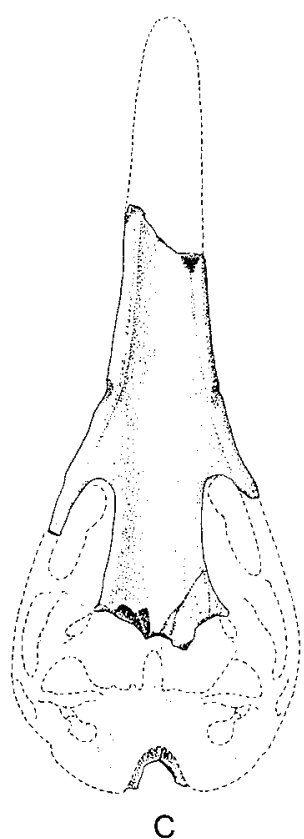

C

\section{$5 \mathrm{~cm} \perp_{\perp \perp \perp \perp \perp \perp \perp\rfloor}$}

FIG. 4. - Drawings of the palatal aspect of Zaglossus sku1ls. a, Zaglossus bruijini; b, Zaglossus robusta (T.M. Z2031), c, Zaglossus "Proechidna" robusta; Pm, premaxilla; Af, anterior palatine fenestra; Mx, maxilla, Mg, median groove; Ic, infraorbital canal; Tc, temporalis crest; Onf, orbitonasal foramen; Fo, Foramen pseudovale; Ty, tympanic cavity; Tf, Temporal foramen or cana1; Fsp, foramen stylomastoideum primitivum; $\mathrm{Fj}$, jugular foramen; Cp, crista parotica (c, after Dunn 1895).

portion of the optic fissure continues anteroposteriorly as a shallow groove. This groove terminates in a small orbitonasal foramen that transmits $V_{l}$.

The base of the orbit is bounded inferiorly by the lateral edge of the palatine bone. Superior to this crisply defined edge is a sill-like expansion of the orbital wall that transmits the infraorbital nerve and artery to the opening of the canal.

Ear region (Plate 1 d)

The small, shallow, triangular tympanic cavity is tilted backwards relative to the horizontal plane of the skull. The posteroinferior border of the squamosal forms one side of a deep, crescent-shaped depression for the origin of the detrahens mandibulae muscle. The area immediately anterolateral to the tympanic cavity is markedly inflated. The posteroexternal edge of the swollen petrosal merges with the posterior 

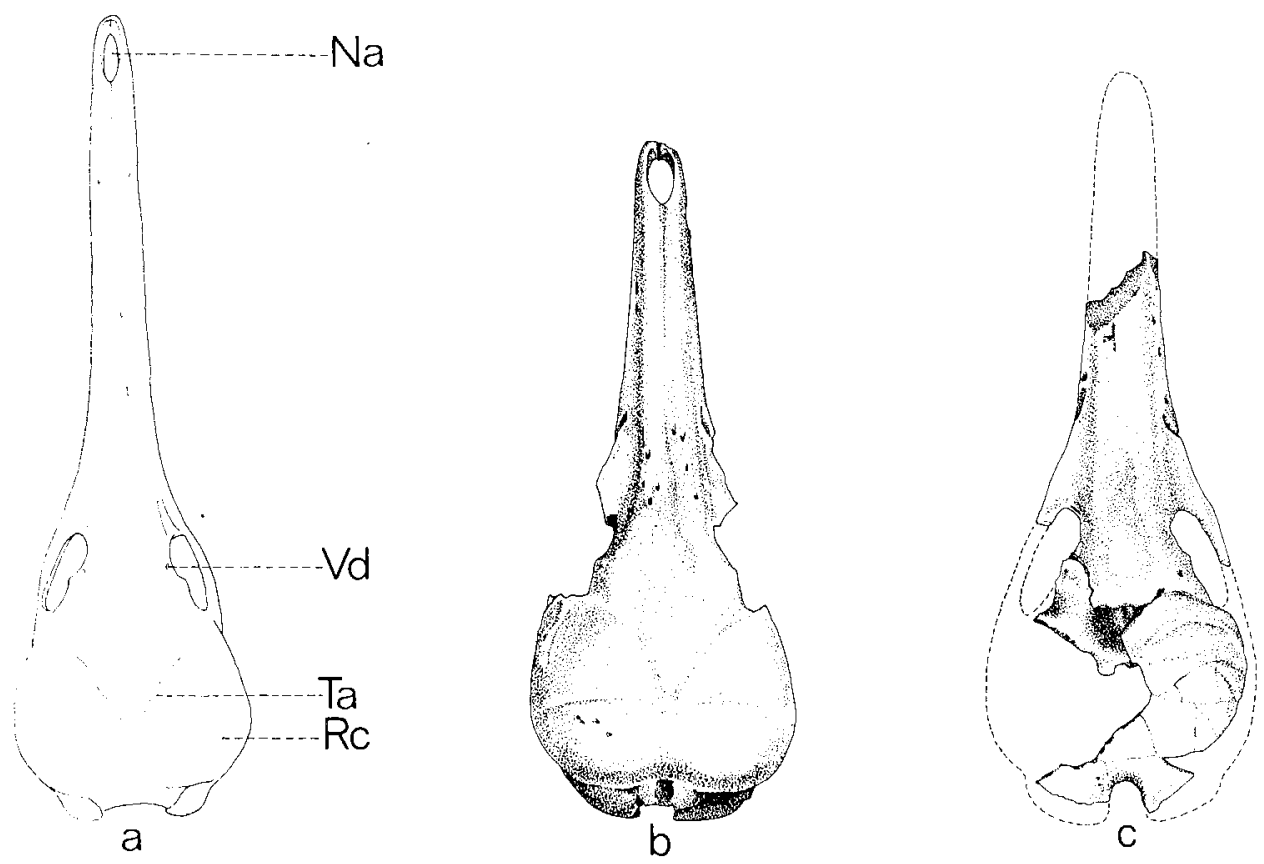

$5 \mathrm{~cm}\left\llcorner\left.\perp_{1}\right|_{1} \perp_{\perp}\right\rfloor$

FIG. 5. - Dorsal Aspect of Zaglossus sku11s. a, Zaglossus bruijni; b, Zaglossus robusta (T.M. Z2031); c, Zaglossus robusta; Vd, diploic vein; Ta, trapezius anterior crest; Rc, Rhomboideus cervicis crest (c, after Dun 1895).

edge of the squamosal defining the lateral side of the tympanic cavity. The posterior border of the tympanic cavity consists of a low, narrow crest composed of the crista parotica (paroccipital process) and its lateral extension, the processus hyoideus. The hyoid process forms the ventral arch of the posteriorly directed foramen stylomastoideum primitivum. A shallow notch divides the more delicate processus hyoideus from the crista parotica. The medial border of the tympanic cavity is formed by the lateral edge of the epipterygoid. The relatively sma11, triangular tympanic cavity is very shallow, deeper posteriorly than anteriorly, and is defined from the petrosal by a faint marginal crest anteromedially and anterolaterally. The epipterygoids form a low, rounded margin having no appreciable lateral overhang.

The posteromedial border of the cavity opens into a canal formed by an overhang of the posterolateral edge of the epipterygoid and crista parotica, the "tuba eustachii ossea" of Gaupp (vascular canal of Simpson, 1938).

The shallow, narrow recessus epitympanicus extends anterosuperiorly to lie outside the 1 ateral border of the tympanic cavity. The crista and sulcus facialis is well developed. The fissura petropterygoidea, usualiy located at the apex of the tympanic 
Peter Murray

cavity, is absent. A median vascular groove extends from the base of the parotic crest to the anterior border (apex) of the cavity. This terminates in a small foramen (visible on one side only) representing the structure Simpson (1938, p.4) termed "dubious canals". The tympanic fossa is a round, shallow depression in the posterolateral portion of the tympanic cavity. The apertura tympanica canalis facialis is relatively large and lies superficial to the lateral margin of the ear.

Palate

Suture lines in the basicranium and palate are entirely obliterated. The large jugular foramen is merged with a more posterior opening or "hypoglossal fenestra". Varying degrees of fenestration in the vicinity of foramina and elsewhere is a distinctive feature of modern Tachyglossus and Zaglossus skulls. The separation of the true jugular foramen from the hypoglossal fenestra is indicated by a hook-like process of the basioccipital. The thin basiphenoid is perforated by small foramina for the internal carotid arteries. The posterior margins of the epipterygoids are delicately notched and appear squarish in outline. A short, narrow "U"-shaped median palatal cleft divides the palatines and epipterygoids at the extreme posterior end of the palate. The palatine bones project posteriorly to cover the entire medial border of the epipterygoids. The paired epipterygoids and palatine bones form the posterior portion of a broad oval basin that continues anteriorly as the palatal arch. A series of small posterior palatine foramina pierce the palatine bones at the level of foramen pseudovale. These continue anteriorly to the level of the optic fissure. The palatines become narrowest slightly posterior to the root of the maxillary process of the malar. The palate is deeply arched at this point. The inferolateral surfaces of the malar roots display wide, shallow grooves that accommodate a large branch of the facial vein. An ascending branch of the facial vein is carried in a deep groove that lies anterior to the root of the malar along the side of the rostrum. It continues to course in an obliquely superior direction.

Three faint, transverse crests are visible in the roof of the deeply arched palate. The lateral margin of the palate is thick and rounded. These smooth edges appear to roll progressively inwards to the end of the rostrum. A rod-1ike nasal septum extends beyond the posterior border of the oval anterior palatine fenestra.

VERTEBRAL COLUMN

\section{Axis (PIate 2e)}

The axis is stoutly proportioned with a broad anteroposteriorly flared neural spine serving in part for the attachment of the rectus capitus dorsalis major muscles. The neural canal is nearly circular. The odontoid process is a short, wedge-shaped protuberance terminating in a pair of low crests. The anterior articular facets are broadly oval in outline. Their surfaces describe shallow arcs that grade superiorly into the neural lamina. The inferior borders of the articular surfaces extend inferiorly below the main body of the vertebra. The large circular transverse canals are located in the base of each relatively narrow, tapering transverse process. These open near the lower middle portion of the vertebral body. A deep, broad groove near the terminus of each transverse process indicates the attachment of the rectus capitus lateralis longus muscle.

\section{Cervical Vertebrae (Plate 2e)}

The remaining cervical vertebrae are represented by $\mathrm{C} 3-4$. The neural spine of $\mathrm{C} 3$ is equal in height to that of the axis. The neural lamina are thin and narrow. The narrow, cylindrical neural spines of $\mathrm{C} 3$ and slightly shorter C4 project vertically. The neural canals are triangular in shape. The posteriorly swept transverse processes are broadly overlapped by the transverse process of the preceding vertebrae. Passages for the spinal nerves are completely bridged foramina located in the posterior portion of the base of each neural lamina. The centra of the cervical vertebrae are 

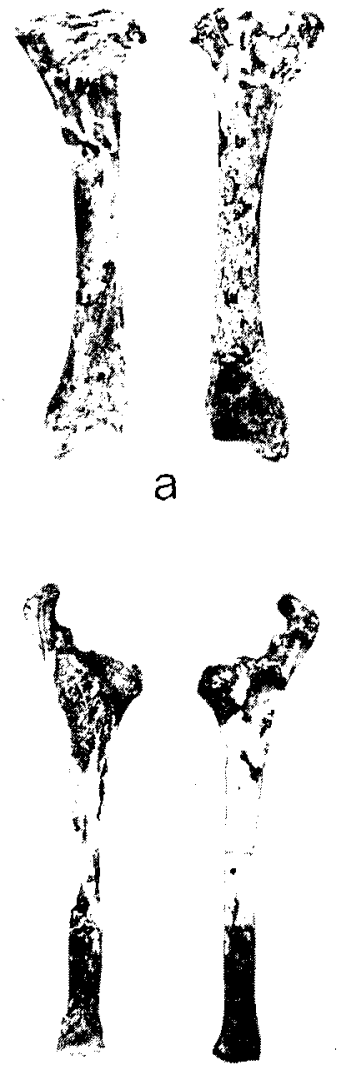

b

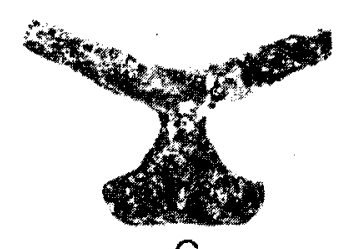

C
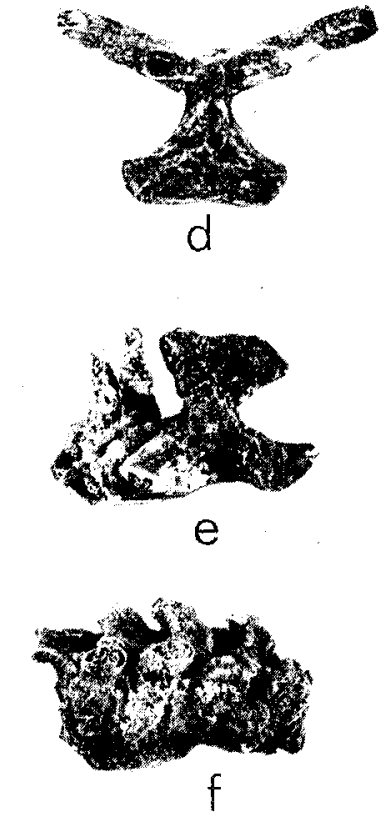

$\mathrm{MM}$
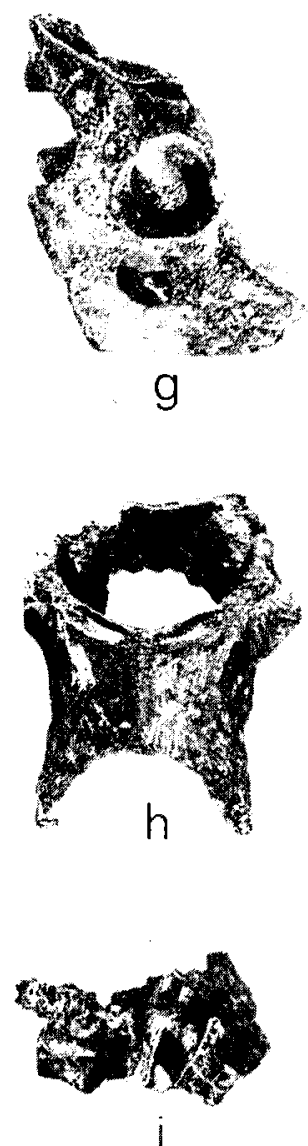

PLATE 2. - Postcranial elements of 22031. A, posterior and anterior aspects of right tibia; b, left fibula; c, clavicles and episternum (ventral); d, clavicles and epistermum (dorsa1); e, axis, C2-3; $f$, thoracic vertebrae 10-14; $\mathrm{g}$, pelvic girdle (1atera1); h, pelvic girdle (ventral); i. thoracic $15-16$ and lumbar 1 vertebrae.

dorsoventra11y compressed.

Thoracic Vertebrae (P1ate 2f)

The thoracic vertebrae are in varying states of preservation. T5 has a low crest leading posteriorly to the neural spine. The broken neural spine base suggests 
Peter Murray

a low, caudally directed spine. There is a broad anterior extension of the neural arch bearing shallow notches anteriorly. The base of the centrum is incipiently rounded. A large formen for the spinal nerves is present. The transverse processes are circular in section, as indicated by their broken bases. These probably represent small peg-like projections. The neural canal is nearly circular. A thin lamina bears an oval thickening on each side representing the prezygapophyses. The centrum has a deep, circular parapophysis on the lateral margin of each side.

T6-9 are poorly preserved. T10-14 are articulated fragments within a block of matrix. The more erect neural spines are somewhat hook-shaped and more robust than those of the preceding series. The bases of the prezygapophyses are stout and the crescentic articular surfaces are laterally directed. The centra are oval in outline. The neural canal is slightly more oval than round.

T15-16 are in articulation with L1. The last thoracic vertebra is missing the neural spine and arch. The neural spine of T15 is broader anteroposteriorly than any of the previous vertebra. The centrum and neural arch are both oval.

Lumbar Vertebrae (Plate 2i)

Lumbar 1 is represented by a centrum and a fragment of the right prezygapophysis. The centrum is oval; the body gently waisted. Well developed costal processes are present below the bases of the transverse processes.

\section{Sacra1 Vertebrae}

Sacral 1 is fused to the base of the ilia by its costal processes. The centrum is longer, deeper and more rounded than L1.

\section{PECTORAL GIRDLE}

Clavicles (P1ate 2c, d)

The stout, moderately bowed clavicles are fused to the episternum. The distal articulations are damaged, but it is probable that the clavicles were relatively short. The attachment of the clavicles at the apex of the episternum creates an approximately 90 degree angle. The anterior surfaces of the clavicles are broad and roughened for the attachment of the trapezius and deltoid muscles. Each clavicle bears a deep, oval articular surface for the epicoracoids on the internal medial aspect. The left articular surface is broader and lies slightly lower than the right. The external or ventral surface of the clavicles are broad and flattened. They are triangular in section.

Episternum (P1ate 2c, d)

The short, bell-shaped episternum displays a large, median (pectoralis)

tubercle. The posterior side of the episternum is rugose. Articulation with the sternum is denoted by a shallow, concave, elliptical joint cavity.

\section{SCAPULA (P1ate 1b)}

Description of the anatomical landmarks of the humerus and scapula is based on Jouffroy, Lessertisseur and Saban (1971), McKay (1895) and Wilson and McKay (1894).

The basically triangular, flat scapula becomes narrow and rounded immediately superior to the glenoid fossa. The inferior portion consists of a large glenoid fossa and a stout, oblique, posteriorly projecting coracoid process. The anterior edge of the blade is produced anteroinferiorly into a prominent acromion process. The inferior border of the acromion forms the upper edge of a large, semicircular, supraglenoid notch. The acromioclavicular joint surface is triangular and deeply concave. A broad flange of bone superior to the joint cavity represents the attachment of the acromiotrachelian muscle. The apex of the joint cavity is formed by two merging crests that 
continue transversely across the medial supraspinous surface of the blade of the scapula forming a well-defined ridge for the attachment of the omohyoid muscle. The broad, flat area directly inferior to the omohyoid crest is occupied by the supraspinatus muscle. This region is traversed by a shallow vascular groove. The mesoscapular (spinous) border is rounded and relatively thick.

The robust coracoid process is rectangular in section. The coracoprocorocoid joint surface is broadly oval, concave superiorly and narrow and flat inferiorly. The glenoid fossa is wide, deep and "C"-shaped in outline. A strong supraglenoid tubercle for the proscapulohumeralis muscle lies above the glenoid fossa. The posteroexternal side of the scapula presents a convex, narrowly triangular surface for the attachment of the subscapularis muscle. A low, rounded crest defining the anterior border of this surface represents the origin of the long head of the triceps muscle. Anteriorly, a deep, broad fossa for the infraspinatus muscle is bounded by the spinous (anterior) border.

\section{HUMERUS (P1ate 1c)}

Powerful forelimb musculature is expressed by the stout, widely flaring epicondyles and tuberosities of the short, flat humeri. There is considerable torsion between the plane of the tuberosites and head; a difference amounting to approximately 50 degrees. The posterior surface of the diaphysis is nearly flat. A low crest for the triceps muscle extends from the inferior tubercle of the entotuberosity (lesser tuberosity) to the ectepicondyle. The triceps scar consists of low, complex ridges and reticulations over much of the posterior surface of the shaft. The round entepicondylar foramen is positioned centrally near the base of the entepicondyle. The opening is smaller on the dorsal aspect. A prominent ridge extends from below the midregion of the humeral head to become the sharply defined external dorsal border of the shaft and leading edge of the ectepicondyle. The concavity produced by this deeply concave external border is occupied by the brachialis muscle.

The entotuberosity is developed into a stout crest having tubercles on its superior and inferior extremities. The superior tubercle for the insertion of the coracobrachialis muscle is largest of the two. The smaller, inferior tubercle takes the insertion of $M$. teres major. The broad entepicondyle is strongly crested for the origin of the flexor muscles. It is deeper and more robust than the ectepicondyle. Below the entepicondylar foramen, a broad, shallow excavation represents the origin of the flexor digitorum communis muscle.

The capitulum is narrow and rounded dorsally. Distally, it becomes constricted, then expands laterally and superiorly into a kidney-shaped surface on the anteroventral side. The anterior opening of the entepicondylar foramen consists of a large circular depression continuing posteromedially into a canal of much smaller dimensions.

The anterior border of the humerus is a prominent crest extending from the middle of the anterior surface of the entepicondyle to the ectotuberosity. It flares into a broad deltoid crest immediately inferior to the ectotuberosity. The distal portion of the ectotuberosity is missing on both humeri.

The medial (internal) surface consists of a broad, shallow depression for the coraco-brachialis superficialis muscle. This accentuates the lower portion of the anterior crest and extends its lower border to the extremity of the entepiocondylar crest. The extremity of the ectepicondyle is missing on both humeri. A narrow, rounded ridge for the attachment of flexor carpi radialis is situated directly inferior to the entepicondylar depression. A wide intercondylar notch is defined laterally by the capitulum and medially by the flexor carpi radialis tubercle.

Between the tuberosities, immediately inferior to the head, a deep, broad, lunate 
Peter ilurray

depression denotes the attachment of the coracobrachialis profundus and supracoracoideus muscles.

The crescentic humeral head projects dorsally beyond the surface of the diaphysis. Medially, the head is merely a thickening in the center of the tuberosities.

\section{INNOMINATE (Plate $2 \mathrm{~g}, \mathrm{~h}$ )}

The ilia are missing from the innominate bones. The pelvic inlet is high and narrow. Large fenestrae perforate the oval acetabulae. The ischia are long and broad with high, rounded tuberosities. Together, the tuberosities form a "U"-shaped notch ventrally at the ischio-pubic juncture. The long pubic symphysis is marked by a substantial crest for the attachment of the rectus abdominus aponeurosis and an apparently very broad gracilis muscle. Deep, elliptical joint cavities for the epipubic bones extend from the midline of the anterior face of the pubis to approximately a third of the distance to the anterior inferior iliac spine. The pectineal (pubic) tubercle is rounded and prominent. A thick crest on the anterior border of the acetabulum represents the origin of the rectus femoris muscle. The base of the ilium is triangular in cross-section. The ventral surface of the ilium is shallowly excavated to accommodate the iliacus muscle. A deep semilunar notch is formed by the projection of the inferior iliac spine below, and the ventral surface of the ilium superiorly. The depth of the notch is accentuated by the outline of the base of the first sacral vertebra.

\section{FEMUR (Plate la)}

The femur diaphysis is markedly compressed anteroposteriorly. The trochanters are torsioned slightly around the plane of the condyles to approximately 16 degrees. The neck is well developed. The greater trochanter is higher than the lesser and is more robust to the extent that it can be seen. The head of the femur is hemispherical, with a slight flattening in the area reserved for the fovea in Eutherians.

The flattened anterior surface of the femur shaft is marked by two shallow excavations on either side of a low, rounded central convexity. The greater trochanter continues inferiorly for approximately two-thirds of the length of the shaft in the form of a narrow crest. The crest grades into the shaft producing the upper limb of a smooth, concave profile that continues inferiorly to the prominently external projection of the lateral condyle. The medial border of the femur shaft is concavoconvex in profile. The medial condyle is disposed laterally so that the internal border of the shaft extends beyond a broad, flat surface for the attachment of the tibial collateral ligament.

The patellar surface is an elongated, narrow, nearly rectangular region defined superiorly by a transverse, shallow, elliptical depression. The articular surface of the medial condyle is slightly flattened inferiorly, becoming more sharply curved superiorly. The intercondylar notch is square and deep. The lateral condyle is moderately saddle-shaped on the inferior surface becoming more rounded superiorly.

The posterior surface of the lesser trochanter grades inferolaterally into a shallow, circular depression representing the attachment of the caudofemoralis muscle. Superiorly, there is a deeper, lunate depression for the insertion of the obturator externus muscle.

\section{TIBIA (Plate 2a)}

The tibiae are long and relatively slender. The proximal articular surface is broad and oval in outline. The distal end expands gradually from the base of the shaft into a relatively large articular surface. The medial malleolus is a robust, 


\section{Tasmanian Pleistocene Spiny Anteater}

conical process, rounded at its distal surface. It deviates gradually from the midline to a point nearly in line with the medial side of the proximal (condylar) articular expansion. In profile it is demarcated from the anterior surface of the tibia by a crest-like extension of the edge of the distal articular surface. The rounded, prominent tibial crest grades into the shaft at approximately one-third the distance to the distal articulation.

The origin of the tibialis anterior muscle is formed by a deep, triangular excavation having an arched, overhanging superior border. A less well developed depression medial to the tibial crest represents the origin of the extensor hallucis longus muscle. On the superoposterior surface of the shaft, a broad, rectangular muscle scar bounded medially by a prominent crest and terminating superiorly in a small conical tubercle, represents the attachment of the powerful popliteus (rotator fibulae) muscle. A thick crescentic muscle scar located imnediately inferior to the rotator fibulae crest takes the insertion of the semitendinosus muscle. Distally, a deep, elongated, triangular sulcus accommodates the tendon and insertion of the tibialis posterior muscle. Part of the fibular head articulates with a narrow, rounded surface on the lateral aspect of the proximal end of the tibia. The articular surface for the medial condyle is larger than the lateral counterpart. The flatmed surface is trapezoidal in outline. The posteromedial edge presents a slightly raised surface suggesting an intercondylar eminence. Medially, a shallow depression represents the attachment of the posterior cruciate 1igament. A depression anteromedial to the edge of the medial condylar joint surface may represent the position of the anterior cruciate ligament. The lateral condylar surface is flat and kidney-shaped in outline. There is a fine, transitional crest between the lateral edge of this and the fibular articular surface. A shallow, transverse groove for the patellar ligament separates the condylar surface from the beginning of the tibial crest.

\section{FIBULA (P1ate 2b)}

The fibulae are long, slender bones with a large, low profile articular surface and a high, hook-like flabelliform process. The shaft is nearly circular in section, save a moderate flattening of the external surface. The fibulae are slightly bowed anteroposteriorly.

The flabelliform process presents a rounded thickening at its sumit. Between this and the articular surface is a small thin, blade-like prominence. A wide triangular excavation of the internal surface of the crest and its attachment to the shaft represents the insertion of the rotator fibulae muscle. The anteriorly directed conical protuberance on the flabelliform crest is for the attachment of the Iateral patellar ligament. The internal surface and posterior border of the flabelliform process is roughened and crested for attachment of the flexor muscles. The proximal fibular articular head is a complex surface having two contact planes. It is trapezoidal in outline and wedge-shaped in section. The dorsal surface consists of a narrow, triangular surface for the external edge of the lateral condyle of the femur. The larger, internal surface articulates with the lateral tibial facet previously described.

An elongated depression halfway down the shaft represents the lower attachment of the rotator fibulae muscle. A deep, circular pit for the interosseous ligament is located on the anterior contact surface for the tibia. The distal articular surface is nearly circular in outline, shallowly concave and inclined posteriorly.

\section{COAPARATIVE MORPHOLOGY}

Cranium

Skulls of Zaglossus bruijini are longer, narrower and more delicately constructed 
than Z2031. Specimens of zaglossus bruijni may exceed the length of the known fossil forms by as much as $38 \mathrm{~mm}$ ( $V$ an Deusen and George, 1959). The most obvious differences pertain to the shape and dimensions of the rostrum and palate. The rostrum of Zaglossus bruijni is relatively longer, narrower and more strongly down-turned. This uniform curvature, measured from the posterior border of the epipterygoids to the inferior surface of the premaxilla, conforms to a nearly perfect arc that can be expressed in terms of the degrees of a segment of a circle (figures 6, 7). Measurements of a limited series suggests that the rostrum of $Z$. bruijni becomes less downcurved as the total length of the skull increases. The curvature of the rostrum in the fossil does not conform to a smooth arc and is more accurately described as an obtuse angle of 163 degrees with vertex at the infraorbital canal. I have treated this as a simple arc in order to compare the specimen with $Z$. bruijni. Different allometric principles appear to be in operation between the two species. Calculations (table 2) imply that a specimen of $Z$. bruijni having the same length of rostrum as the fossil form would possess a more strongly down-curved beak. Similarly, a specimen of $Z$. bruigin having a rostrum and skull width comparable to the fossil form would possess an enormously long rostrum (figures 8,9, table 2).

The rostrum is pointed in $Z$. bruijni whereas the blunt proboscis of the fossil form agrees with Tachyglossus. Marked differences between the fossil form and $Z$. bruijni can be seen in the cross-sectional contour of the palate (figure 10). In $Z$. bruigni, the narrow palate resembles an inverted "V". The Montagu fossil

FIG. 7. - Scatter diagram plotting radius of curvature of the palate against degrees of arc subtending $\theta$ for Z. bruijni (dots) and Zaglossus sp. (T.M. Z2031); $r$, radius in millimetres; $\theta$ in degrees.

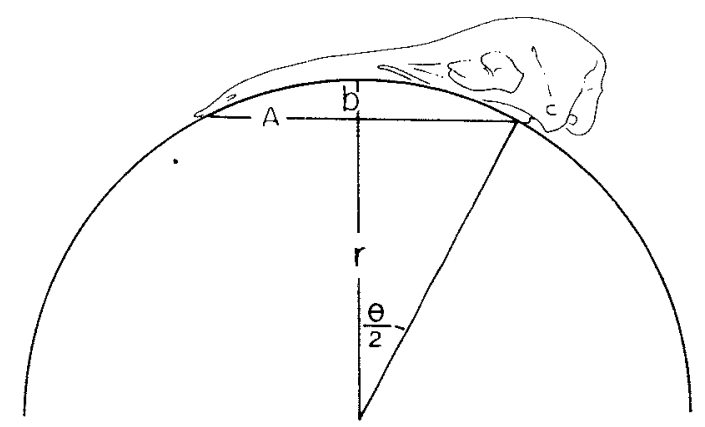

FIG. 6. - Method of determining rostral decurvation in Zaglossus. $\mathrm{A}=$ cord; $b=$ interval between vertex of arc and cord; $\theta=$ subtending degrees of arc calculated as:

$$
\theta=2 \sin ^{-1}\left(\frac{A}{2 r}\right)
$$

$r=$ radius, calculated as:

$$
r=\frac{1}{2}\left(b+\frac{\left(\frac{A^{2}}{2}\right)}{b}\right)
$$

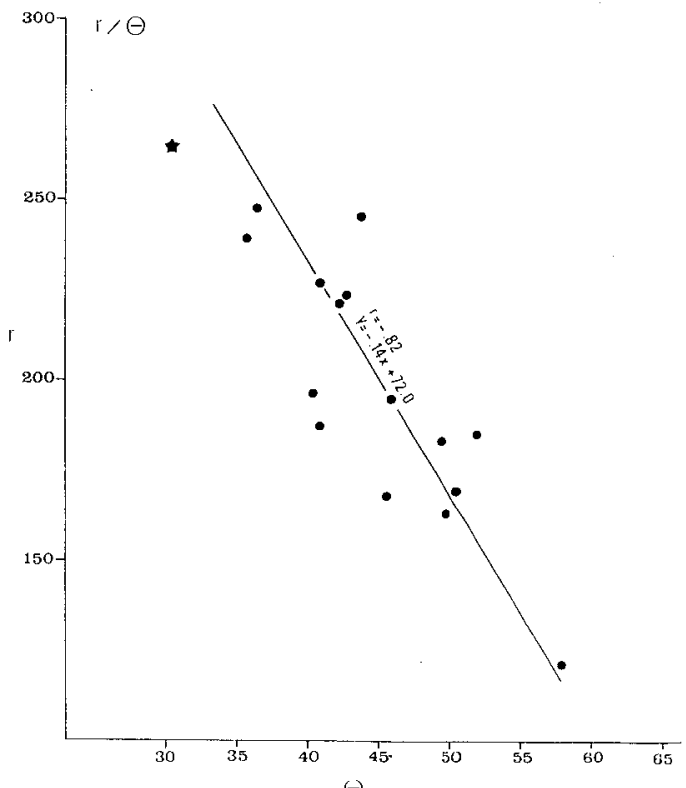


has an inverted "U"-shaped palatal section, relatively deeper, but similar to that of Tachyglossus.

Numerous foramina located near the base of the dorsal side of the rostrum are absent in Zaglossus bruijni. The nasal aperture is shorter and broader in the fossil than in 2 . bruijni, and the premaxillary suture is open in the fossil but fused in the specimen in my possession. Perhaps age-related, the premaxillary suture is frequently open and mobile in Tachyglossus aculeatus setosus.

The overall size and shape of the braincase is similar in the fossil and

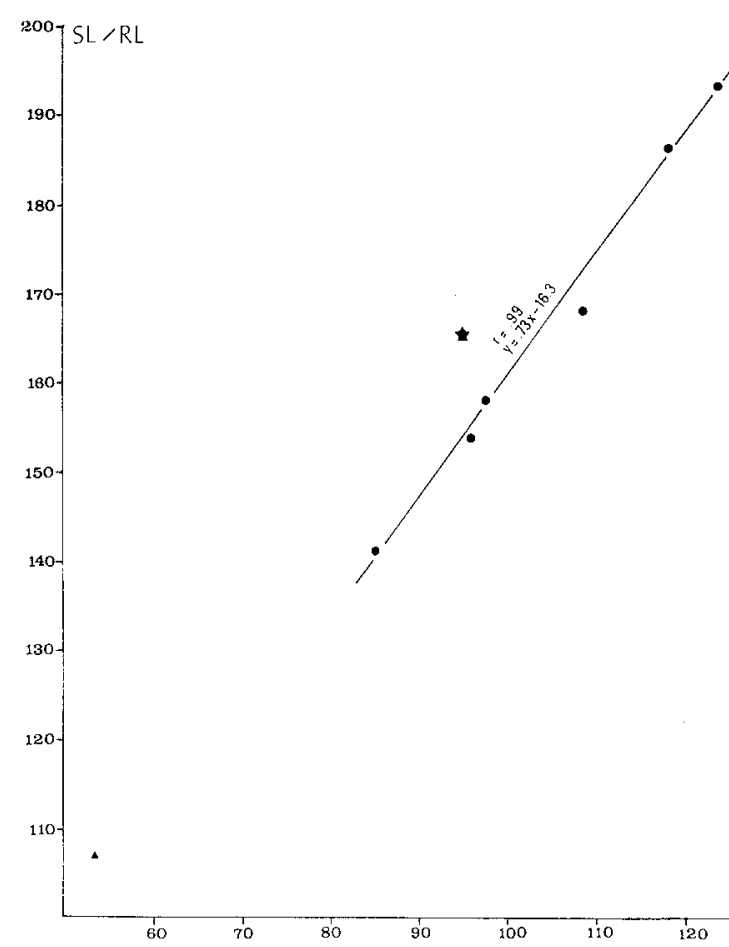
Zaglossus bruijini. The braincase of Tachyglossus is relatively larger, broader and lower in proportion to the length of the rostrum. The fossil, Tachyglossus and Zaglossus share the tendency for varying degrees of fenestration of the skull.

The articular surfaces of the occipital condyles are broader in 2 . bruigni than the fossil and Tachyglossus (fig. 11). Differences in the orbit are primarily proportional. The orbital walls in $Z$. bruijni converge towards the proportionally narrower palate to the extent that the entire orbital fissure is visible from a palatal view. In the fossil, full view of the optic foramen is obscured by the edge of the palate.

The ear regions differ in several respects. In the fossil form, the roof of the tympanic cavity is tilted backwards, relative to a horizontal plane drawn from the crista parotica to the tip of the rostrum (fig. 12). The roof of the cavity is horizontal in $Z$. bruijni and Tachyglossus. The tympanic cavity is also shallower and relatively smaller in the fossil than Tachyglossus and to a lesser extent Zaglossus bruijni. Unlike $Z$ 2031, the tympanic recess is clearly defined in Tachyglossus and 2. bruijini by an extensive anteromedial overhang of the epipterygoids and an anterolateral crest of the squamosal (fig. 13). All three species show the characteristic triangular shape of the cavity. Tachyglossus and 2 . bruijni

lack the conspicuously swollen petrosal
aced roof of the cavity in the fossil rostrum against condylobasal length of skul1s of Zaglossus bruijni (dots), Tachyglossus (triangle), and Zaglossus robusta (T.M. Z2031)(star); scale in millimetres.

region that contributes to the obliquely displaced roof of the cavity in the fossil
form. The recessus epitympanicus is enclosed by the lateral border of the tympanic cavity in both living forms. Other details of the ear region are similar.

The foramen stylomastoideum primitivum is directed laterally in 2 . bruijni in contrast to the more posteriorly directed opening seen in the fossil and Tachyglossus. This difference in the orientation of the foramen is apparently due to a more 


\section{Peter Murray}

transversely directed processus hyoideus and more posterior disposition of the squamasol border in the fossil form. In 2 . bruijni the inferior border of the squamosal commences medially in a gentle arc. In the fossil, and to a lesser extent in Tachyglossus it is sharply angled medially.

The posterior margins of the epiterygoids of the fossil appear considerably broader than in $Z$. bruijni. This is due to a continuation of the posterior palatine processes along the posterior epipterygoid margins (figure 14). The contact of the palatine processes and the epipterygoids is delineated by a shallow notch that contributes to the fluted appearance of the squarish posterior palatal margin. In Z. bruijni and Tachyalossus the notch is deeper and the palatine process is considerabiy shorter.

Proechidna robusta Dun, 1895, is very similar to the Montagu fossil echidna (figures 3-5). The GuIgong fossil is only slightly larger than the $7^{0}$ Montagu form and displays the same features of morphology that serve to differentiate the Montagu Zaglossus from Z. bruijini. These characteristics include the smoothly arched, deep palate, the broad dorsoventrally compressed rostrum, the morphology of the malar region in relation to the grooves for the facial veins, the presence of a large nasofrontal depression, and the overall proportions of the skuIl.

Dun (1895, p.122) estimated that the total length of the Gulgong skull fragment would have been on the order of $265 \mathrm{~mm}$. If the Montagu specimen is used in the restoration, a figure of slightly more than $180 \mathrm{~mm}$ is obtained (figures 3-5, table 2). While this is within the maximum range of length in $Z$. bruijni, the relative proportions of the beaks of the fossils is more comparable to that of Tachyglossus.

FIG. 10. - Cross-sections of the rostrum and palate of a, Tachygzossus aculeatus; b, Zaglossus bruijni; c, Zaglossus robusta. T.M. Z2031. Note the roof-shaped palatal arch of zagzossus bruijni.
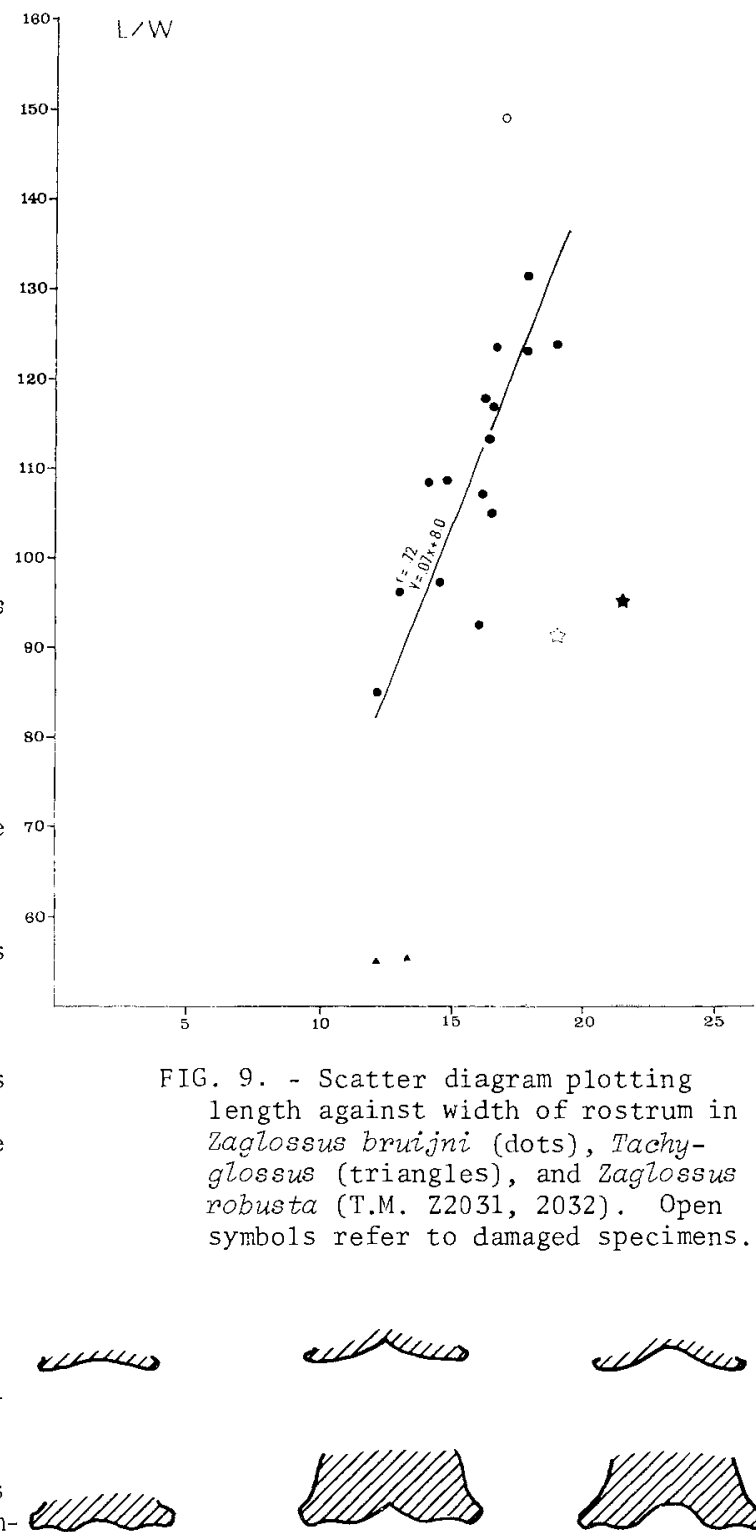

FIG. 9. - Scatter diagram plotting length against width of rostrum in zaglossus bruijni (dots), Tachyglossus (triangles), and Zaglossus robusta (T.M. Z2031, 2032). Open symbols refer to damaged specimens.
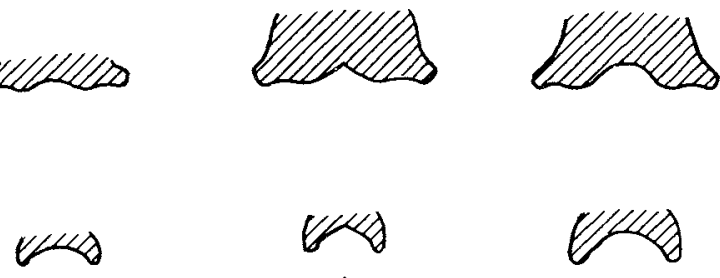

b

C 


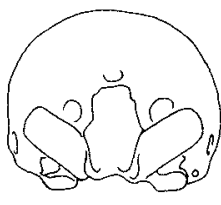

a

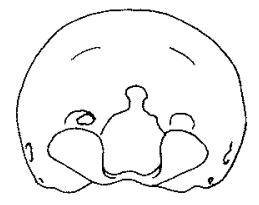

b

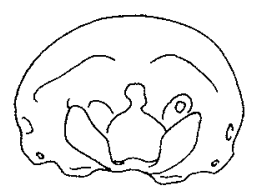

$a$

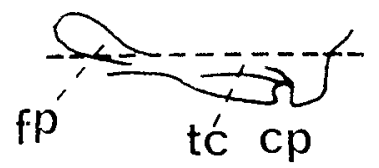

b

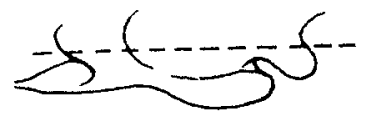
qual sizes to facilitate com Zaglossus robusta (T.M. 22031); b. Zaglossus bruijni and c, Tachyglossus aculeatus.
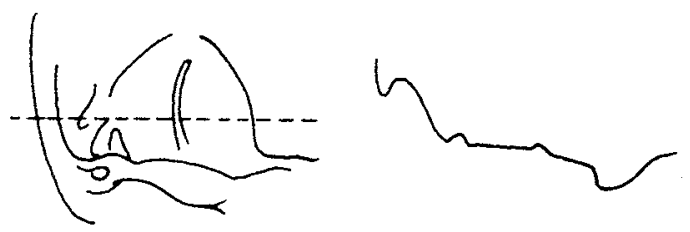

a
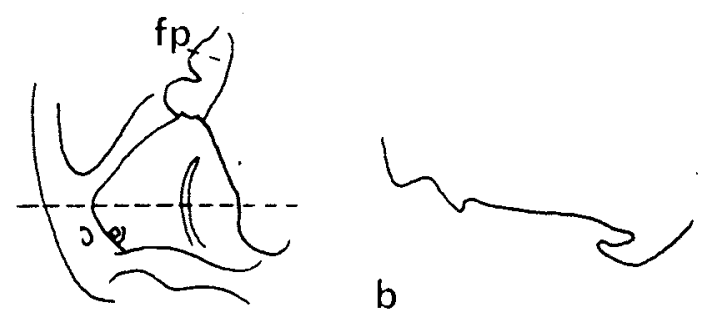

b

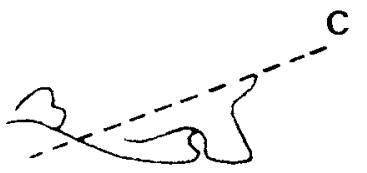

FIG. 12. - Latera1 view of the ear region showing the angle of the petrosal (dotted line) which forms the roof of the tympanic cavity. a, Zaglossus bruijni; b. Tachyglossus aculeatus and Zaglossus robusta (T.M. Z2031). Fp, foramen pseudovale; Tc, tympanic cavity; $\mathrm{Cp}$, crista parotica.

Vertebral Column

The axis of the Montagu fossil differs from that of $Z$. bruijni in several aspects of morphology. The body of the vertebra of the fossil form is relatively broader and shorter. In living Zaglossus the dorsal aspect of the transverse process is markedly flared superiorly. This expansion is not expressed in the fossil axis, which is more like that of Tachyglossus (figure 15). The transverse canals of the fossil specimen are of moderate size and nearly round. They are large and irregularly oval in $Z$. bruijin. In the fossil, the articular facets for the axis are broader and less convex than in Z. bruijni. The neural canal is comparatively small in the fossil. The cervical vertebrae of the fossil form are more robust than those of $Z$. bruijni, having more prominent and heavy crests for muscle attachment. Slight differences in the morphology of the neural spines of the thoracic vertebrae are 
Peter Murray

apparent between the fossil and 2 . bruijni. In the fossil they are stouter and may have been slightly more erect.

The remaining vertebrae are similar except for a difference in overall size. As many features of the vertebrae are subject to considerable variation, these specific morphological contrasts may be of little or no significance. The major difference that can be stated is that of increased size over $Z$. brui,jni. Unfortunately, I have not been able to

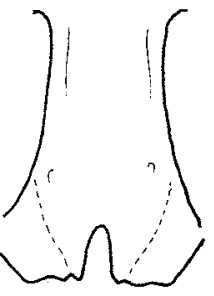

a determine the exact number of vertebrae present.

\section{Pectoral Limb and Girdle}

The ventral (external) surface of the clavicles of the fossil is broader and flatter than 2 . bruijni. The episternum is decidely more flared at the base than the long-beaked New Guinea form, but both the fossil and the living Zaglossus are more alike when compared with the narrow, triangular episternum of Tachyglossus. The pectoralis tubercle is well developed in the fossil and modern Zaglossus but is more ventrally disposed in the latter and Tachyglossus.

The epicoracoid facets on the medial, internal aspect of the clavicles are much deeper, broader impressions in the fossil form. They are almost equal1y represented on both clavicles, whereas $Z$. Bruijni and Tachygtossus have markedly asymmetrical joint cavities. The clavicles of $z$. bruijni also appear to be more acutely bowed, relatively slender and longer.

Differences in the scapula are also present. The glenoid fossa of the fossil and Tachyglossus is comparatively wider than that of $Z$. bmijni. The interior portion of the articular surface is gently rounded rather than tapered as in $Z$. bruijin. The living species have a less prominent supraglenoid tubercle for the proscapulohumeralis muscle. In the fossil form the triceps crest is relatively less prominent. The flange superior to the acromion (supracromical crest) for the acromiotrachelian muscle is comparatively weak in $Z$. bruijni; the omohyoid crest is only faintly visible. Due to the posterolateral flaring of the supracromial crest and concommitant torsion of the

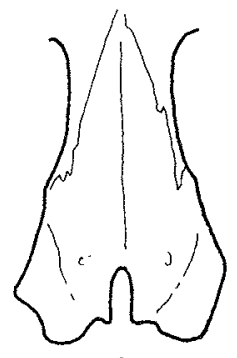

b

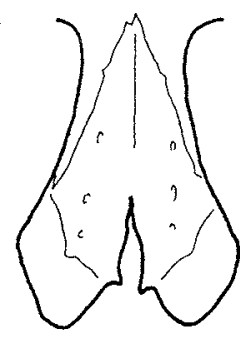

c
FIG. 14. - Outlines of the palatal regions of a, zaglossus robusta (T.M. Z2031) b, Zaglossus bruijni (M9852) and $c$, rachyglossus aculeatus; drawings are scaled to equal sizes to aid comparison.

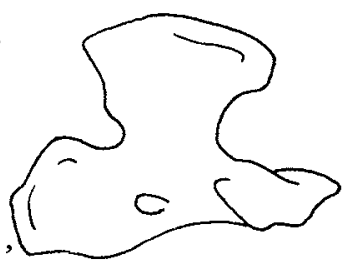

a

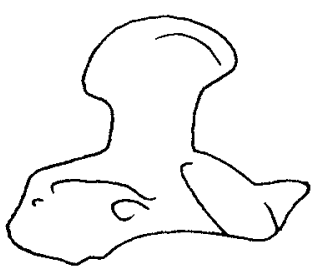

C

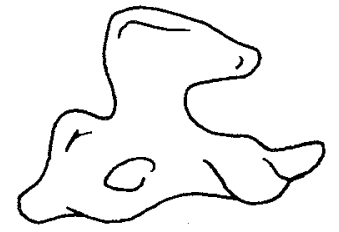

b

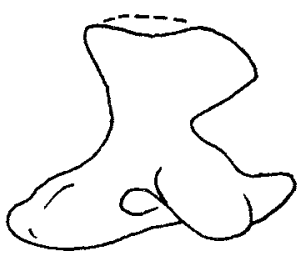

d

FIG. 15. - Outlines of the axis of a-b, Zaglossus bruijni; c, Tachyglossus aculeatus, d, Zaglossus robusta; Note in particular the broad, high crest in the transverse process in 2. bruijni for the attachment of longissimus cervicis. This feature is poorly developed in 22031 and Tachyglossus. 


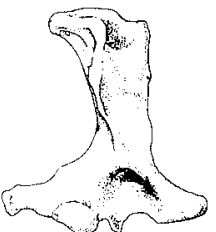

a
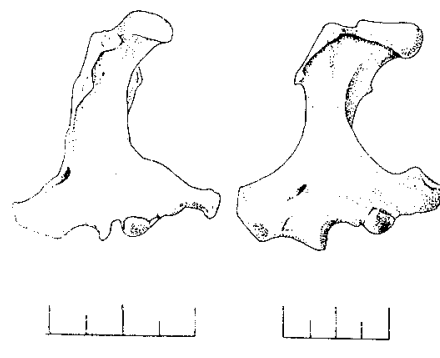

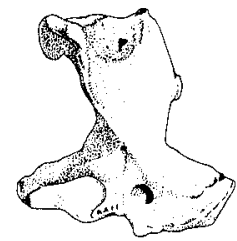

$\mathrm{C}$
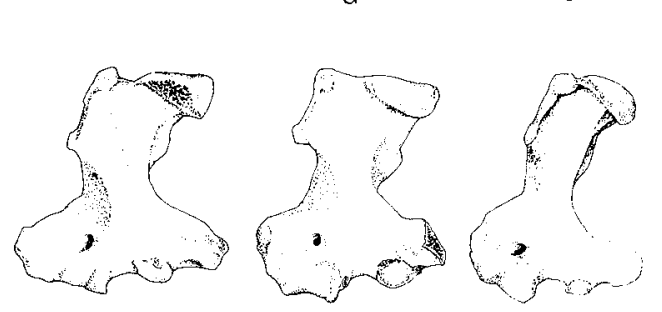

Li!l
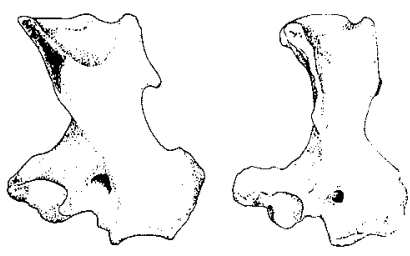

e

$d$

FIG. 16. - Monotreme humeri (right), scaled to equal sizes; a, Omithorhynchus anatinus; b, Tachyglossus aculeatus; c, "Ornithorhynchus maximus" = Zaglossus robusta; c, Zaglossus robusta (T.M. Z2031); d, ZagZossus bruijni. Upper row; posterior aspect; lower row: inferior aspect (c, after Dun 1895).
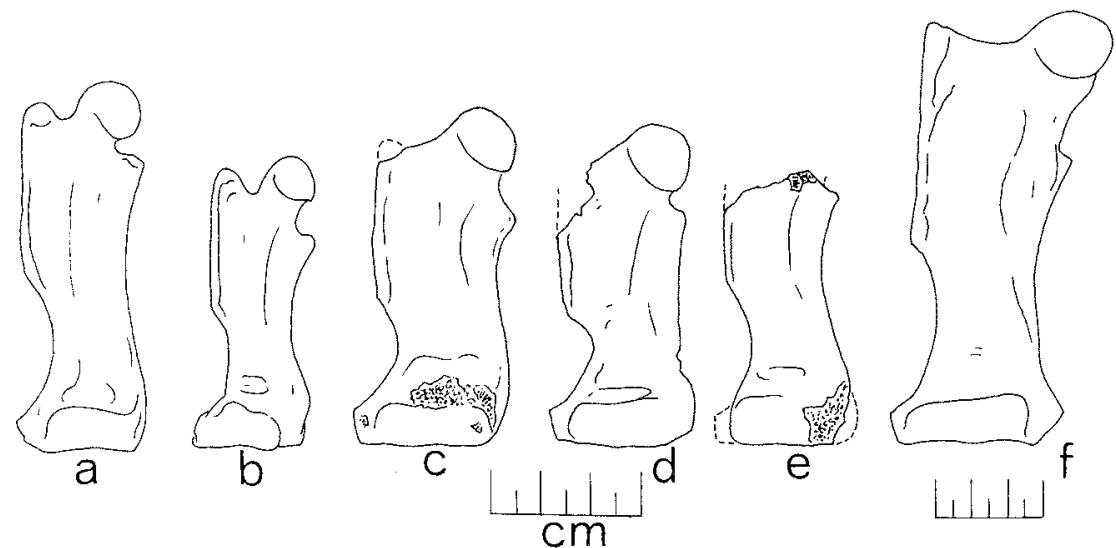

FIG. 17. - Zaglossus femora drawn to scale except for $f$ which is reduced to $3 / 4 \mathrm{x}$ relative to a-e; a-b, Zaglossus bruijni, c, Zaglossus robusta (T.M. Z2031); d, ZagZossus harrissoni (QVM 13 or 1965: 39 : 5)

Zaglossus sp. from Scotchtown Cave, Tasmania (reversed); $f$, Zaglossus hacketti (W.A. Mus. 60: 10:1). (f, after G1auert, 1914). 
acromioclavicular joint surface, the infraspinatus fossa appears deeper in the fossil form.

The humeri of all three species are morphologically similar (figure 16). Compared to $Z$. bruijni the posterior surface of the diaphysis of the fossil form is relatively broader and the entire shaft is proportionally shorter. The lesser tuberosity is more sharply demarcated from the head and is slightly more medially disposed in the fossil humeri. In $Z$. bruijni, the proscapulohumeralis muscle attachment is defined by a deep excavation of the superior portion of the posterior surface of the shaft. A crest extending from the lesser tuberosity to the head accentuates this fossa. The same area in the fossil humeri is convex rather than concave and the crest is weakly developed. The head of the humerus is broader in the fossil form.

In 2 . bruijni the anterior border (brachialis crest) is a sinuous line. In the fossil species and rachyglossus the anterior border is a smooth arc. The entepicondyle of 2 . bruijui is shorter and more rounded than the fossil form. The deltoid tuberosity of 2 . bruijni is situated relatively lower than either the fossil or Tachygzossus.

Dun (1895) described the right humerus of a fossi1 monotreme (Aust.

Mus. F51453) as the remains of a giant platypus (Ormithorhynchus maximus). The morphology of this humerus is clearly different from living ornithorhynchus anatinus, closely resembling the Pleistocene ZagZossus humeri from Montagu (figure $16 \mathrm{c}, \mathrm{d}$ ).

There are fewer differences between the Gulgong and Montagu humeri than either shows with Zagzossus bruijni. The entepicondyle of the Gulgong specimen is slightly narrower and the dorsal opening of the entepicondylar foramen is larger in diameter. The differences between the Montagu and Gulgong specimens are within the normal range of morphological variation for Zagzossus bmijni or Tachyglossus aculeatus. The dimensions of the Gulgong humerus are almost identical with the Montagu specimens.

The Gulgong humerus can be readily distinguished from that of ornithorhynchus anatinus. The entepicondyles of platypus humeri are much narrower, the entepicondylar foramen opens dorsally on the extreme margin of the entepicondyle, rather than near the centre of the base of the process as in tachyglossids generally; the shaft of the platypus humerus is narrower than the Gulgong form, or any tachyglossid, and is oriented more perpendicular to the long axis of the epicondyles. The platypus humerus has a proportionally much larger fossa surrounding the entepicondylar foramen, a considerably narrower intercondylar notch, a much broader deltoid crest, 5 to 10 degrees 
more torsion of the head around the plane of the epicondyles and presents a deep fossa for the brachialis muscle.

The fossil humerus is from the same deposit in Canadian Lead Mine as the skull and axis of Proechidna robusta. It is highly probable that the humerus belongs to the same individual, and is reassigned to the Tachyglossidae: Zagrossus (Froechidna) robusta Dun 1895 (Mahoney and Ride, 1975, p.28).

\section{Pelvic Limb and Girdle}

The pelvic inlet is higher and narrower in the fossil species. The pubic angle is more acute, forming a wide "V" rather than a rounded profile. The pubic symphysis is proportionally much longer; the ischial rami form a relatively narrower and shorter arch. It is rounded at the juncture with the pubic symphysis rather than distinctly "V" shaped as in Z. bruijni. The ischial tuberosities are comparatively broader, shorter and less divergent distally in the fossil and the crest for the attachment of the rectus femoris muscle is relatively longer and tapers gradually into the ilia. In 2. bruijni the tubercle is abruptly relieved from the surface of the ilium. The facets for the attachments of the epipubic bones are more prolonged in the fossil, more closely approximated medially and terminate a greater distance superiorly from the pectineal tubercle.

The Mammoth Cave innominate specimen differs from the Montagu form in its much larger size and more oval acetabulae. It shares with the Montagu fossil a difference in the morphology of the tubercle for the rectus femoris muscle (Glauert, 1914).

The Montagu femora are considerably more compact than those of 2 . bruijni and Tachyglossus. The intertrochanteric notches are less distinct in the fossil than in the living species. The anatomical neck is less distinct and is considerably broader than the head at its junction with the shaft in contrast to the living species. The lesser trochanter is conical and blunt rather than crested as in 2 . bruijni.

The Montagu femora are conspecific with the specimen from King Island (2. harrissoni).

The range of variation in these femora (figure $17 \mathrm{c}$, d) is similar to that of the living Zaglossus species.

The femur from Scotchtown cave is only slightly more robust than that of a large female specimen of $Z$. bruijni figured in plate IX by Gervais (1878).

The femora of Zaglossus hacketti (Glauert, 1914) are much larger than the specimens from Tasmania. In addition, they display several distinctive features:

1) the shaft is relatively slender

2) the epicondyles are relatively smaller,

3) the internal epicondyle is more prominent,

4) the lesser tuberosity is disposed inferiorly,

5) the greater trochanter extends further latera1ly.

The tibia of the living and extinct species of tachyglossids are distinguishable primarily on the basis of size. The tibial crest is relatively more prominent and rounded in the fossil form. The medial articular surface is level with the plane of the superior portion of the crest. In 2 . bmijni the surface lies above the tibial crest. The tibial shaft in the fossil is slightly more concave on the medial side when compared with 2 . Briigni. The origin of the tibialis anterior muscle is more deeply excavated in the fossil than in $Z$. bruijini or Tachygrossus. 
Peter Murray

The tibia of the Mammoth Cave specimen is a very stout, proportionally more massive bone than the other fossil or living tachyglossids. The concavity for the tibialis anterior muscle appears to be poorly expressed as it is in some living Zaglossus specimens. The shaft of the Mammoth Cave form is symmetrically biconcave rather than being strongly concave on the medial side only. Other differences include the very massive, short, less medially disposed styloid process.

The major morphological differences in the fibulae between the fossil and living species pertain to the shape of the flabelliform process. In the Montagu fossil this process is stouter, more rounded and all but devoid of thin, boney flanges. It is hook-shaped rather than squarish at its termination. The conical hook-1ike process for the lateral 1igament is weakly developed in Tachyglossus and Zaglossus bruijni.

\section{DISCUSSION}

The Montagu and Gulgong fossils share a variety of morphological features with Zaglossus bruijni and Tachyglossus aculeatus. Certain other characteristics are unique to the large P1eistocene echidna.

Characteristics shared with Tachyglossus include:

1) rounded palatal arch; broad, blunt, relatively short, dorsoventrally compressed rostrum,

2) deep nasofronta1 depression,

3) 1 arge temporal cana1; posteriorly directed opening of foramen stylomastoideum primitivum,

4) narrow, tapered transverse processes on the axis and cervical vertebrae,

5) long, narrow occipital condyles,

6) compactly built humeri,

7) wide glenoid fossa of the scapula,

8) U-shaped outline of joined ischial rami.

Features shared with Zaglossus bruijni:

1) large overall size,

2) down-curved rostrum,

3) presence of a deep groove for the ascending facial vein,

4) bell-shaped episternum with prominent pectoralis tubercle,

5) shape and proportions of the neurocranium,

6) deep vacuity for the detrahens mandibulae muscle,

7) relatively small, shallow tympanic cavity.

Unique morphological features include:

1) overall robustness,

2) angled rather than arcing decurvation of the rostrum and palate; rostrum is distinctly less downcurved than Zaglossus bruijni, in proportion to its length,

3) tympanic cavity directed obliquely caudad, extremely shallow; swollen petrosal, lacks fissura petropterygoidea, recessus epitympanicus extends laterally beyond the margin of the tympanic cavity,

4) large, numerous nasofrontal foramina,

5) small epipterygoids,

6) extension of the palatine bones posteriorly to cover the medial border of the epipterygoids. 


\section{FUNCTIONAL MORPHOLOGY}

The fossil form obviously exhibits a mosaic of morphological features that emphasize the great similarity of the two living genera. An attempt to explain the adaptive significance of some of these features may help clarify the position of the fossil form relative to Zaglossus bruijni and Tachyglossus.

Evidence suggests that the fossil species (excluding $Z$. hacketti) occupied a niche intermediate between those of the living genera. The shapes of the beaks of the living forms express their capacities to exploit special food resources (figure 18). The broad, slightly decurved rostrum of the fossil form was moderately efficient for vertical probing and upward prying, but optimum for low angle feeding. The strongly decurved, narrow and pointed rostrum of Zaglossus bruijni is best suited for vertical probing in a relatively soft substrate.

The short, slightly upturned broad, blunt rostrum of Tachyglossus is a modification for prying up rocks and woody debris, shallow probing and low angle feeding.

Both living genera are very adaptable and employ a variety of horizontal and vertical feeding postures (Van Deusen and George, 1969; Brattstrom, 1973). Zaglossus bruigni is the most limited because the long, curved beak is less efficient for vertical reaching and low angle probing and prying.

The fossil species displays certain features in common with Tachyglossus that pertain to the powerful digging action of the forelimbs and to the mobility and strength of the atlanto-occipital joint. The broader, more shallowly arching occipital condylar joint surfaces of 2 . bruijni may reflect greater mobility of the head at the expense of loss of efficient support for lifting and prying with the beak. The long decurved rostrum of $Z$. bruijni necessitates increased vertical mobility of the head to reach the same levels as a form with an equally long but less down curved rostrum.

The powerful forelimbs of the fossil form are clearly not adaptations to support greater weight along since the animal is only marginally larger on a 1 inear basis than the much more gracile living species. Its proportions are closer to Tachyglossus suggesting an ability to dig and tear into resistant materials. This ability is reduced in zaglossus bruijni.

The fossil forms were probably entomophagus echidnas that exploited ants, termites and perhaps 1 arge beetle and moth 1 arvae living in rotted wood. The relationship of the fossil zaglossus to the New Guinea long beaked anteater is probably too remote to suggest a clinal variant analogous to the New Guinea Tachyglossus aculeatus lowesi and $T$. aculeatus setosus, though similar trends are apparent. T. a. Zowesi contrasts with $T$. a. setosus in having a more slender rostrum and, also 1ike 2 . bruijni, there is a trend towards the reduction of the 3 rd and 4 th claws of the pes (Thomas, 1885, p.338). These features may have evolved in Tachyglossus since the isolation of New Guinea and Tasmania from the Australian Mainland in early post-glacial times.

\section{ACKNOWLEDGEMENTS}

Dr. James Hopson, University of Chicago Department of Anatomy, offered valuable advice on anatomical terminology and brought to my attention important reference material. Dr. Ken Campbe11, Department of Geology, Australian National University, made helpful comments on the manuscript. I wish to thank them both. I also extend my gratitude to Margaret Galbraith and Glenys Isaac for typing the manuscript. 


\section{Peter Murray}

\section{REFERENCES}

Bartholomai, A., 1972: Aspects of the evolution of the Australian marsupials. Proc. R. Soc. Qd, 82, V-XVIII.

1975: The genus Macropus Shaw (Marsupialia: Macropodidae) in the Upper Cainozoic deposits of Queens1and. Mem. Qd Mus., 17(2), 195-235.

Brattstrom, B., 1973: Social maintenance behaviour of the echidna, Tachyglossus aculeatus. J. Mammal., 54(1), 50-70.

Dun, W.S., 1895: Notes on the occurrence of monotreme remains in the Pliocene of New South Wales. Rec. Geol. Surv. N.S.W., IV, 118-126.

Gervais, P., 1878: OSTEOGRAPHIE DES MONOTREMES VIVANTS ET FOSSILES. Librarie Scientifique et Maritime, Paris. 1-56.

Gi11, E. and Banks, M., 1956: Cainozoic history of Mowbray Swamp and other areas of northwestern Tasmania. Rec. Q. Vict. Mus., 6(N.S.), 1-41.

Glauert, L., 1910: The Mammoth Cave. Rec. W.A. Mus. and Art Gazlery, 1, 11-36. , 1914: The Mammoth Cave (Zaglossus hacketti sp. nov.). Rec. W.A. Mus. and Art Gallery, I (iii), 244-251.

Hi1debrand, M., 1968: - ANATOMICAL PREPARATIONS. Univ. Calif. Press, Berkeley and Los Angeles, viii+100 pp.

Jouffroy, F., Lessertisseur, J., and Saban, R., 1971: Particularites musculaires des monotremes, in TRAITÉ DE ZOOLOGIE, XVI, Fasc. III, Masson et C ${ }^{i e}$ Grasse, P. (ed.) Paris. $679-836$.

Krefft, G., 1868: On a new and gigantic species of echidna. Ann. Mag. Nat. Hist. I (ser. 4), 113-114.

Kuhn, Hans-Jurg, 1971: Die Entwick1ung u. Morphologie des Schadels von Tachyglossus aculeatus. Abhandzungen der Senkenbergischen Naturforchenden Geselzschaft, $528,1-224$.

Mahoney, J.A., and Ride, W.D.L., 1975: Index to the genera and species of fossi1 mammalia described from Australia and New Guinea between 1838 and 1969. W.A. Mus. Spec. Publ. 6, 1-247.

Mckay, W. 1895: The morphology of the muscles of the shoulder girdle in monotremes. Proc. Linn. Soc. N.S.W., 9, 263-360.

Murray, P., and Goede, A., 197 $\overline{7}$ : Pleistocene vertebrate remains from a cave near Montagu, N.W. Tasmania. Rec. Q. Vict. Mus., 60, 1-30.

Owen, R., 1884: Evidence of a large extinct monotreme (Echidna Ramsayi Ow.) from the Wellington Breccia Cave, New South Wales. Phil. Trans. R. Soc. Lond., 185, $273-275$.

Scott, H., and Lord, C., 1921: Studies in Tasmanian Mammals, 1iving and ext $\overline{i n c t}$, Number V, Zagiossus harmissoni sp. nov. Pap. Proc. R. Soc. Tasm., 15-16.

Simpson, G.G., 1938: Osteography of the ear region in monotremes. Amer. Mus. inovitates, $978,1-15$.

1945: The principles of classification and a classification of mammals. Buzl. Amer. Mus. Nat. Hist., 85, 1-350.

1948: The beginning of the age of mammals in South America. BulZ. Amer. Mus. Nat. Hist., $91,1-232$.

Tandler, J., 1902: Zur vergleichenden anatomie der Kopfarterien bei den Mammalia. Anatomische Hefte., 18, 327-386.

Tedford, R., 1966: A REV $\overline{I E W}$ OF THE MACROPODID GENUS STHENURUS. University of Ca1ifornia Press, Berkeley and Los Angeles, 1-71.

Thomas, 0., 1885: Notes on the characters of the different races of echidna. Proc. 2007. Soc. Lond., 329-339.

VanDeusen, H., and George, G., 1969: Notes on the echidnas (Mammalia: Tachyglossidae) of New Guinea. Amer. Mus. Novitates, 2383, 1-23.

We11es, S.P., and Gregg, D.R., 1971: Late Cretaceous marine reptiles of New Zea1and. Rec. Canterbury Mus., 9(1), 1-111.

Wilkinson, C.S., 1887: Geological Survey of New South Wales. Report of Progress for 1886 by the Geological Surveyor in Charge. An. Rep. Dept. Mines N.S.W. 1886, 4, 1-212. 
Wilson, J., and McKay, W., 1894: On the homologies of the borders and surfaces of the scapula in monotremes. Proc. Linn. Soc. N.S.W., 8 (3), 377-388.

\section{APPENDIX}

MEASUREMENTS OF FOSSIL ZAGLOSSUS MATERIAL FROM MONTAGU, TASMANIA

Skull

\begin{tabular}{ccl} 
mm. & no. & \multicolumn{1}{c}{ description } \\
165.0 & 1 & Condylobasal length \\
155.0 & 2 & Occipitobasal length \\
139.0 & 3 & Length, epipterygoids-premaxi1la \\
95.5 & 4 & Infraorbital canal to premaxilla \\
11.8 & 5 & Width rostrum behind external nares \\
21.6 & 6 & Width rostrum anterior to the root of zygomatic arch \\
23.2 & 7 & Width of palate at orbital fissure \\
26.7 & 8 & Width palate at foramen pseudovale \\
59.7 & 9 & Width neurocranium at the anterior edge of temporal foraminen \\
11.3 & 10 & Width across epipterygoids \\
$13.9 / 5.6$ & 11 & Diameter anterior palatine fenestra \\
$7.7 / 3.5$ & 12 & Dimensions median palatal cleft \\
$11.8 / 7.3$ & 13 & Dimensions tympanic cavity \\
$10.3 / 8.1$ & 14 & Dimensions jugular foramen \\
$2.0 / 2.0$ & 15 & Dimensions foramen stylomastoideum primitivum \\
3.5 & 16 & Thickness maxillary process of the palate \\
4.7 & 17 & Depth of palatal arch at the level of the anterior root of malar \\
$13.7 / 5.6$ & 18 & Dimensions external nares \\
5.9 & 19 & Height rostrumbehind external nares \\
14.1 & 20 & Height of rostrum at the anterior root of the zygomatic arch \\
20.2 & 21 & Height of rostrum at the level of the infraorbital foramen \\
45.0 & 22 & Maximum height of braincase \\
$4.5 / 2.8$ & 23 & Dimensions temporal foramen \\
$3.4 / 3.4$ & 24 & Dimensions of foramen pseudovale \\
$5.6 / 3.5$ & 25 & Dimensions optic fissure \\
$3.0 / 2.0$ & 26 & Dimensions infraorbital canal \\
$17.7 / 2.1$ & 27 & Dimensions facial vein groove \\
$23.0 / 12.5$ & 28 & Dimensions occipital condyles \\
$22.1 / 18.3$ & 29 & Dimensions foramen magnum \\
70.2 & 30 & Length neurocranium \\
& &
\end{tabular}

Pectoral girdle and limb

a. Clavicles and epicoracoid

$\begin{array}{lll}33.1 & 1 & \text { Length episternum (includes height of clavicles) } \\ 34.6 & 2 & \text { Maximum width episternum } \\ 9.1 & 3 & \text { Minimum width episternum } \\ 11.2 / 4.6 & 4 & \text { Dimensions procoracoid articular surface } \\ 9.0 & 5 & \text { Depth cord of clavicular arch } \\ 10.0 / 7.6 & 6 & \text { Diameter clavicles } \\ 66.5 & 7 & \text { Combined length of clavicles } \\ \text { b. Scapula (Two individuals: 1 left and 1 right) }\end{array}$

b. Scapula (Two individuals: 1 left and 1 right)

$\begin{array}{cccl}\text { 1eft } & \text { mm. } & & \\ 22.6 & 19.2 & \text { no. } & \text { description } \\ 8.0 & 3.5 & 8 & \text { Width subacromial notch } \\ 20.3 & 19.0 & 9 & \text { Depth subacromial notch } \\ 19.0 / 21.8 & 17.5 / 18.5 & 10 & \text { Width scapula above glenoid fossa } \\ & 23.6 & 11 & \text { Dimensions glenoid fossa } \\ & & 12 & \text { Length coracoid process }\end{array}$


Peter Murray

$\begin{array}{ccc}\text { left mm. } & & \text { description } \\ 16.2 & 13 & \text { Minimum width coracoid process } \\ 20.2 & 14 & \text { Maximum width coracoid process } \\ 65.3 & 15 & \text { Length acromion to coracoid }\end{array}$

c. Humerus (Two individuals: two right)

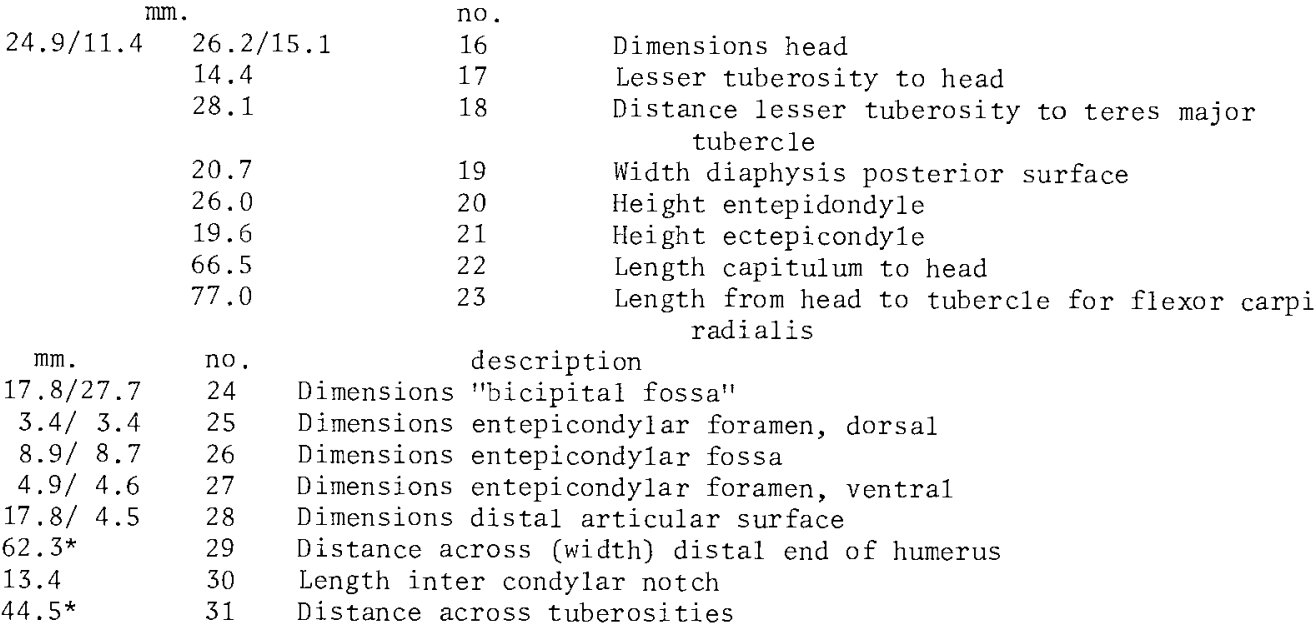

Innominate and pelvic limb

a. Innominate

$22.8 / 20.9$

$12.7 / 9.1$

Diameter acetabulum

$13.6 / 11.0$

Diameter acetabular fenestra

61.3

Diameter obturator foramen

40.5

Puboischium

46.0

Height of ischium posterior to acetabulum and obturator foramen

Length pubis

48.0/36.7 7 Diameter of pelvic inlet

$20.8 / 16.0 \quad 8$

$41.8 \quad 9$

$24.1 \quad 10$

Dimensions centrum sacra

Width across ischia

Depth ischipubic notch

$38.1 \quad 11$

Width across ischia

$16.2 / 4.4 \quad 12$

Dimensions epipubic bone articulation

Length pubic "symphysis"

$46.5 \quad 14$

b. Femur

$16.0 / 16.8$

Width across anterior inferior spine

$77.0-16$

$5.8^{*} \quad 17$

$38.7 \quad 18$

$21.0 \quad 19$

$24.5 \quad 20$

$35.8 \quad 21$

$37.5 \quad 22$

$13.6 / 13.6 \quad 23$

$13.5 / 11.1 \quad 24$

$8.6 / 9.5 \quad 25$

Dimensions head of femur

Maximurn length, head-lateral condyle

Length intertrochanteric notch

Length greater trochanter

Distance lesser torchanter from head

Width diaphysis femur

Width distal articular surface femur

Width across trochanters

Dimensions medial condyle

Dimensions 1ateral condyle

Dimensions interocondylar notch 
mm. no.

c. Tibia and fibula

$\begin{array}{ccl}96.0 & 26 & \text { Maximum length tibia (medial malleolus to head) } \\ 28.9 / 22.9 & 27 & \text { Dimensions proximal articular surface tibia } \\ 9.2 & 28 & \text { Width diaphysis tibia } \\ 7.7 & 29 & \text { Width flexor groove } \\ 17.6 & 30 & \text { Width distal end tibia } \\ 5.1 & 31 & \text { Length styloid process } \\ 107.0 & 32 & \text { Maximum length fibula } \\ 14.3 & 33 & \text { Length flabe11iform process } \\ 8.5 / 13.5 & 34 & \text { Dimensions proximal articular surface } \\ 5.9 & 35 & \text { Width diaphysis fibula } \\ 6.7 & 36 & \text { Width distal articular surface }\end{array}$

Axial skeleton

a. axis

27.5

34.0

11.2

$5.0 / 5.0$

42.7

$16.2 / 12.5$

7.2

8.3

$12.0 / 17.0$

8.9

28.6

13.0

description

Maximum length tibia (medial malleolus to head)

Dimensions proximal articular surface tibia

Width diaphysis tibia

flexor groove

Length styloid process

Maximum length fibula

Dimensions proximal articular surface

Width distal articular surface

Length neural spine

Maximum height vertebra

Minimum 1ength

Dimensions transverse cana1

Maximum length vertebra

Dimensions anterior articular surface

Length odontoid

Width neural arch

Dimensions neural canal

Height odontoid

Distance across anterior articular surfaces

Height transverse process 